NBER WORKING PAPER SERIES

\title{
THE INTERACTION OF SPENDING POLICIES, ASSET ALLOCATION STRATEGIES, AND INVESTMENT PERFORMANCE AT UNIVERSITY ENDOWMENT FUNDS
}

\author{
Keith Brown \\ Cristian Tiu \\ Working Paper 19517 \\ http://www.nber.org/papers/w19517 \\ NATIONAL BUREAU OF ECONOMIC RESEARCH \\ 1050 Massachusetts Avenue \\ Cambridge, MA 02138 \\ October 2013
}

This study has benefited greatly from input provided by all of the participants at the NBER conference on "How the Great Recession Affected Higher Education", which was held at Cambridge, MA in September 2012. We are particularly grateful for the comments of Jeffrey Brown, Stephen Dimmock, Elroy Dimson, Thomas Gilbert, Will Goetzmann, Caroline Hoxby, Christopher Hrdlicka, and Scott Weisbenner. We would also like to express our appreciation to the following individuals connected to the endowment fund industry who have provided us with valuable resources as well as their comments: John Griswold and Bill Jarvis (Commonfund), Kenneth Redd (NACUBO), Uzi Yoeli and Bruce Zimmerman (UTIMCO), Andrea Reed and Scott Wise (Covariance Capital), Tim Nguyen (University of Connecticut Foundation), Ed Schneider (University at Buffalo Foundation), Chris Adkerson (Mercer) and Larry Tavares (TAP Inc.). Finally, we also thank Sergey Maslennikov and Woongsun Yoo for their research assistance. The views expressed herein are those of the authors and do not necessarily reflect the views of the National Bureau of Economic Research.

NBER working papers are circulated for discussion and comment purposes. They have not been peerreviewed or been subject to the review by the NBER Board of Directors that accompanies official NBER publications.

(C) 2013 by Keith Brown and Cristian Tiu. All rights reserved. Short sections of text, not to exceed two paragraphs, may be quoted without explicit permission provided that full credit, including $(\mathrm{C}$ notice, is given to the source. 
The Interaction of Spending Policies, Asset Allocation Strategies, and Investment Performance at University Endowment Funds

Keith Brown and Cristian Tiu

NBER Working Paper No. 19517

October 2013

JEL No. G23,I22,I23

\begin{abstract}
Using data for more than 800 college and university endowment funds over 2003-2011, we provide a comprehensive analysis of the spending policies used in practice as well as how frequently and why those mandates are revised over time. Given the long-term and relatively static nature of the investment problem faced by the typical educational institution, existing theoretical models of endowment management predict that the permanent portion of the stated spending policy should be highly stable. However, we find that half of the endowments revised their rules at least once and, on average, about a quarter of the sample changed their spending policies each year, implying a retention rate far lower than expected. We show that larger endowments with lower historical portfolio returns and lower past payout levels are more likely to alter their future spending formulas, but that institutions having the ability to invoke special appropriations on a temporary basis are less likely to make adjustments to their permanent rules. Further, we document that both spending rule changes and asset allocation adjustments persist over time and that, consistent with hypothesized behavior, the former tends to lead the latter. Finally, while there is some evidence that endowment funds as a group produce superior returns relative to their policy benchmarks, we show that there is no difference in benchmark-adjusted performance between institutions that either did or did not change their spending rules.
\end{abstract}

Keith Brown

University of Texas

kcbrown@mail.utexas.edu

Cristian Tiu

SUNY at Buffalo

ctiu@buffalo.edu 


\section{The Interaction of Spending Policies, Asset Allocation Strategies, and Investment Performance at University Endowment Funds}

\section{Introduction}

Suppose that you are contemplating the launch of a new investment management firm. Before determining the myriad logistical details involved with staffing and running the business, you must first make a basic decision on the general approach to managing assets that the company will adopt. Consider two alternative schemes for organizing the business:

Approach 1: Develop a thorough understanding of what the clients expect to accomplish by investing their financial capital and then design an investment portfolio (i.e., asset allocation and security selection strategies) that represents the optimal solution to the clients' "problem"; or:

Approach 2: Design the specific elements on an investment portfolio (i.e., asset allocation and security selection strategies) and then market that portfolio to investors for whom it represents an appropriate solution to their financial problem.

While both organizational formats are used widely in practice (e.g., private wealth management firms exemplify Approach 1; the mutual fund industry is typical of Approach 2), the question remains as to which is the more conceptually valid method. For many investors, Approach 1 represents the proper sequence of events in that it starts with an understanding of what the investor is trying to accomplish before proceeding to form a portfolio that represents the optimal ex ante solution to that problem. Conversely, although Approach 2 suffers the potential criticism of reversing that order (i.e., forming the portfolio "solution" first), it is often the more cost-effective scheme, particularly for those investors with relatively small amounts of capital to manage.

For firms managing institutional assets (e.g., defined-benefit pension plans, endowment funds and foundations, sovereign wealth funds), resolving this question is critical if for no other reason than the amount of invested capital involved. ${ }^{1}$ Defined-benefit pension plans and university

\footnotetext{
${ }^{1}$ For instance, by the end of 2005, professional managers for three of the most prominent institutions - mutual funds, defined-benefit pension funds, and endowment funds and foundations - controlled $\$ 8.9$ trillion, $\$ 4.7$ trillion,
} 
endowments are particularly interesting to contrast in this respect because both types of institutions face reasonably well-defined, if otherwise dissimilar, investment problems. For example, asset allocations in pension fund portfolios are often made in response to complex asset-liability management problems, with a broad array of client-specific (e.g., annual payout needs, workforce age) and firm- and industry-wide (e.g., plan funded status, legal and regulatory restrictions) factors serving as constraints on the process. Further, this investment decision is complicated by the fact that defined pension benefits are a legally binding obligation of the plan sponsor, which creates and manages the fund portfolio for the purpose of meeting those liabilities, but must also be prepared to cover the shortfall if fund income (or assets) proves to be insufficient. It is for this reason that Merton (2003) argues that the relevant investment risk in pension fund management is not that of the assets alone but rather the volatility of the surplus of fund assets over liabilities.

Endowment funds are even more intriguing entities because they simultaneously combine some of the salient characteristics of other institutional investors with several features that make them truly unique. Like pension funds, the conventional endowment portfolio-as typified by the building and operating funds at a college or university — must be managed with regard to a well-specified set of spending rules. However, as Garland (2005) notes, an important difference between endowment funds and pension plans is that trustees of endowment funds "...expect to preserve their capital for a very long time; trustees of pension funds expect their capital to be consumed (p. 44)." ${ }^{2}$ In fact, endowment funds are among the only economic agents for which the assumption of an infinite investment horizon is not an approximation, making them especially well-suited laboratories for studying management practices under "textbook" conditions. ${ }^{3}$

Given this description, arguably the most significant conceptual challenge that any endowment fund must resolve is the tension that exists between the desire to increase the future wealth of the portfolio - and in so doing help to insure the long-term viability and autonomy of the institution it supports-and the need to provide spending capital for the current generation. Addressing this tension, which can be viewed as the primary investment problem that endowment funds confront, is the chief role of the spending policy, which is the formal statement

and $\$ 1.3$ trillion in assets, respectively. These assets under management statistics are for U.S.-based institutions and come from the Investment Company Institute (mutual funds) and Standard \& Poor's Money Market Directory (pension funds, endowments and foundations).

${ }^{2}$ Swensen (2009), reinforces this point as follows: "Investing with a time horizon measured in centuries to support the educational and research mission of society's colleges and universities creates a challenge guaranteed to engage the emotions and intellect of fund fiduciaries (p. 3, emphasis added)."

${ }^{3}$ There is a well-developed literature addressing the problem of optimal portfolio choice over an infinite planning horizon under the conditions of income consumption; see, for example, Samuelson (1969), Merton (1971), and Bodily and White (1982). 
that the educational institution's governing authority adopts to express its intentions. Despite its apparent importance, though, the topics of how endowment funds are organized and how they determine their spending policies have received remarkably little attention in the literature. Further, much of this research is quite dated; for example, Cain (1960) summarizes the details of a survey of 200 institutions of higher education regarding a variety of operational issues ranging from specific investment holdings to the use of outside advisors and the existence of income reserve accounts. ${ }^{4}$

Still, from what has been written, there are two important hypotheses about the way in which endowments should define and revise their spending policies that remain untested. The first hypothesis involves the relationship between the organization's spending and investment policies and on this matter there are opposing predictions. One side of the argument is typified by Litvack, Malkiel, and Quandt (1974), who concentrate on the more narrow question of how endowment income should be defined so as "...to make investment management independent of the spending decisions of the university (p. 433)", which is consistent with organizational Approach 1 defined above. Other studies reflecting this view include Tobin (1974) and Garland (2005). On the other hand, Dybvig (1999) argues that an endowment's choice of a spending rule should be linked to its asset allocation decision in an explicit and dynamic fashion, while Blume (2010) uses data simulations to conclude that a fund's spending and investment strategies are best determined jointly, which would be more in line with Approach 2. Gilbert and Hrdlicka (2012), who examine the issue of the inter-generational fairness of the spending rule decision, come to a similar conclusion.

The second untested hypothesis from the extant literature on endowment spending involves the identity and temporal stability of the permanent payout policy that a given institution adopts. That is, what is the optimal spending policy in the face of the endowment's specific circumstances and how frequently should that rule be adjusted? On this matter, the theoretical literature that exists is considerably less ambiguous. Specifically, Merton (1993) creates a formal model of an endowment fund as one of several tangible and intangible assets that a university possesses for the purpose of establishing the optimal spending and investment policies the fund should choose. In the context of the current discussion, he shows that (i) the optimal spending rule for any Period $t$ should be a constant proportion of the net worth of the fund in that same period, and that (ii) the proportion of wealth expended is not stochastic given the underlying

\footnotetext{
${ }^{4}$ Cejnek, Franz, Randl, and Stoughton (2012) provide an excellent review of the endowment fund literature, which encompasses a number of relevant topics including the determination of spending policies.
} 
conditions of the model. Thus, absent a substantial change in the institution's circumstances (e.g., the educational and research activities in which it engages), the optimal rule by which any given endowment determines its annual expenditures should not vary over time. Woglom (2003), who expands Merton's conceptual framework to the explore the Tobin (1974) notion of "inter-generational fairness" in more detail, produces a more complex optimal spending rule but one that remains non-stochastic given the endowment's inter-temporal rate of substitution between current and future income needs.

In this study, we extend and test these lines of inquiry by providing a comprehensive examination of which endowment spending policies are used in practice as well as how frequently and why those mandates are revised over time. Starting with an overview of a typical endowment organizational structure, we consider the role that both the institution's spending and investment policies play in the portfolio management process. In particular, we describe an endowment's spending policy as consisting of two distinct elements: the spending rules, which represent the formal set of instructions used to determine the amount of capital that will be paid out of the endowment portfolio on an annual basis, and the policy payout rate, which is the particular percentage level used to convert the general spending rule into a specific dollar disbursement. Given the very long-term horizon of the sponsoring institution, as well as the relatively invariant nature of the present-versus-future trade-off that defines its investment problem, the underlying premise of our investigation is that the endowment spending policy should require modification on a very infrequent basis.

Our analysis is based on an examination of spending, asset allocation, and investment performance data for more than 800 public and private university endowment funds located mainly in North America. The primary database we utilize is constructed from the annual surveys of the organizational structure, spending and investment policies, and spending and investment practices that the National Association of College and University Business Officers (NACUBO) collects from its member institutions. Focusing of the survey years from 2003 to 2011, the period of time for which NACUBO collected information regarding spending rules and policy payout rates, we classify into one of seven broad categories the stated payout rules that every endowment fund adopted in each year. The frequency with which endowments adopt these seven spending rules is not uniform; in fact, the Moving Average rule, which sets the annual payout as a pre-specified percentage of an average of past market values for the endowment portfolio, is used in roughly three-quarters of the cases. Further, we also document that there is a considerable degree of heterogeneity in spending rule adoption practices within the endowment 
sample. Generally speaking, we find significant differences in the formulas favored by funds with disparate payout needs and that larger funds are far less reliant on Moving Average rules than are smaller endowments.

One of the most surprising results in the study is that endowment funds modify their spending policies to a far greater extent than the investment problems faced by the sponsoring institution would seem to warrant. In particular, we show that while half of the funds in the sample maintained the same policy throughout the 2003-2011 period, the other half changed their permanent spending rules between one and eight times; the weighted mean frequency of endowments altering their spending policy in a given year was almost $25 \%$. An analysis of the migration patterns in spending rule adoption practices showed that the various rule categories produced dramatically different likelihoods of being retained or changed from one year to the next; for example, Moving Average rules (and more complex Hybrid formulas involving Moving Average rules) had markedly larger retention rates than did simpler rules, such as payout formulas based on percentage of the income the fund generated in the current year.

Extending this investigation, we consider the effect that the global financial market crisis which began in 2008 had on an endowment's propensity to adjust its spending policy. By focusing on behavior in the post-recession period (i.e., 2009-2011), our analysis documents two significant findings. First, despite the additional funding burdens caused by a substantial loss of market value in their asset portfolios, endowments actually showed an increased tendency to maintain their existing permanent policies following the economic downturn. Second, roughly one in three funds imposed some form of temporary incremental appropriations to supplement their permanent spending rules after 2008. The combination of these effects can be viewed as a rational marginal response to what was perceived as a temporary, albeit severe, perturbation in normal economic conditions.

We also examine the issue of what motivates an educational institution to alter its stated payout policy. Our investigation of the economic determinants of spending rule changes reveals that the larger the endowment is and the lower the return to its portfolio, the more likely it is to make a modification. Also, spending rule changes are significantly and negatively related to historical payout levels, but the percentage of the institution's budget that the fund is responsible for delivering is not a meaningful factor. Our lead-lag analysis of the relationship between spending rule changes and asset allocation adjustments reveals that it is the former that tends to precede the latter and that adjustments to both types of policy are strongly persistent over time. Finally, despite the fact that endowment funds produce strong benchmark-adjusted returns as a 
group, there is no detectable difference in the investment performance between institutions that either did or did not alter their spending rules. Overall, we conclude that the typical educational endowment has changed its permanent spending policy far more frequently than might be reasonably expected and that these adjustments are linked to, or interact with, characteristics of the funds themselves (e.g., level of assets under management, historical payout level) as well as various aspects of the investment practices of the institution (e.g., asset allocation patterns).

The remainder of the paper is organized as follows. In the next section, we provide an overview of how, and by whom, endowment spending rules and investment practices are determined. Section 3 discusses the data we use in our empirical analysis and describes our endowment fund sample, including summary statistics on fund size, annual investment returns, annual payout rates, asset class allocations, and the spending rules that are used in practice. In Section 4 we present a detailed analysis of the way spending policy adoption has evolved over time while Section 5 identifies several economic determinants of these policy modifications. Section 6 examines the interaction between an endowment's spending policy decision, its investment strategy, and the portfolio's investment performance. Section 7 concludes the study.

\section{Spending and Investment at University Endowment Funds}

\subsection{Endowment Organization: A Brief Overview}

Generally speaking, endowment funds are portfolios of assets invested in support of the shortand long-term mission of a particular institution. Within the context of this broad definition, Hansmann (1990) notes that endowments can have several specific purposes, from helping the institution remain financially solvent by providing a source of funding to offset current operating expenses to insuring its continued existence and economic independence into the foreseeable future to enhancing the reputational capital of the sponsoring institution. ${ }^{5}$ As Kochard and Rittereiser (2008) discuss, the presence of endowment funds can be traced back to fifteenth century England, when wealthy donors provided churches and schools with financial gifts intended to support them in perpetuity. In the United States, university endowment investing ostensibly began in the mid-1600s with a real estate gift bestowed upon what is now Harvard University by several of its alumni.

\footnotetext{
${ }^{5}$ Hoxby (2012) proposes a model of the university in which the institution's objective function is to maximize its contribution to the intellectual capital of society. Within this framework, she argues that both endowment funds and tuition subsidies arise naturally in support of that mission.
} 
For most of their existence, educational endowments have been managed under "prudent man" laws, which have historically been rooted in state trust statues, as opposed to federal law, and tended to focus on the disposition of individual holdings rather than the development of the entire portfolio. ${ }^{6}$ As characterized by Sedlacek and Jarvis (2010), the management of university endowments began to gravitate toward the precepts of modern portfolio theory in the 1950s, culminating with the passage of the Uniform Management of Institutional Funds Act (UMIFA) in 1972, which standardized many of the rules regarding the way in which spending and investing could take place. In 2006, the UMIFA statutes were revised further with the Uniform Prudent Management of Institutional Funds Act (UPMIFA). Among other things, UPMIFA updates the old standards, particularly with regard to the level of flexibility the endowment's governing authority has to invest and spend assets, in the absence specific restrictions imposed by the original donor. Under UPMIFA, an institution is permitted to accumulate or spend as much of the endowment fund as the board deems appropriate, even to the point where the current value of the fund falls beneath the original level (i.e., the fund is "underwater").

Figure 1 provides a stylized view of the way in which a typical university endowment is organized. The two main economic actors involved in the process of deploying the fund's financial capital are the University/Endowment Board (i.e., "Board"), which represents the governing authority ultimately responsible for the endowment's assets, and the Investment Committee/Firm (i.e., "Staff"), to which falls the day-to-day responsibilities of designing and maintaining the actual investment portfolio. Broadly speaking, the primary functions of the Board are two-fold: (i) create the policy statements that define the investment problem faced by the university (i.e., the Spending Policy), as well as the way in which the endowment's financial assets should be invested to address this problem (i.e., the Investment Policy); and (ii) monitor the Staff's ongoing operations on a regular basis to insure compliance with those policies. By contrast, the Staff - which may comprise anything from a single individual to representatives of a multi-person committee of the Board (e.g., Yale Investments Office) to an entirely separate operating firm (e.g., University of Texas Investment Management Company) - is charged with the responsibility of managing the fund's assets in the most effective manner possible, within the context of the policy parameters set forth by the Board. ${ }^{7}$ Thus, in the typical endowment there is a clear

\footnotetext{
${ }^{6}$ Indeed, prudent man laws first came into existence with the Harvard College v. Amory case in 1830, which involved a dispute over how investments tied to the Harvard College endowment had been handled.

${ }^{7}$ In its annual survey of educational endowment practices, NACUBO reported that for the 2010 fiscal year, the average number of full-time equivalent professional staff persons employed by the 842 funds in their sample was just 1.5. However, the cross-sectional distribution of professional staffing levels is highly skewed; the mean number of full-time professionals employed by endowments with assets of over $\$ 1$ billion is 10.0; see Walda and Griswold (2011).
} 
delineation between those responsible for defining the investment problem and setting the broad parameters for the investment solution and those who make those mandates operational. ${ }^{8}$

\subsection{Endowment Spending Policy}

We begin by formally defining the spending policy adopted by a particular endowment as consisting of two distinct components: (i) a spending rule, and (ii) a pre-specified payout rate. The distinction between these two entities is that the spending rule defines the general procedure by which the payout amount will be determined, whereas the payout rate represents the specific percentage that is to be applied within the context of the spending rule. For example, during the 2007 fiscal year, Texas Christian University determined their annual endowment payout using a "50/50 Hybrid" approach in which the institution calculated a weighting consisting of (i) $50 \%$ of the dollar amount of the prior year's spending, incremented by the Higher Education Price Index (HEPI) inflation index, and (ii) $50 \%$ of an amount established by taking $5.0 \%$ of an average of the market values of the endowment portfolio over the previous four quarters, starting at of the beginning of the current fiscal year. In this case, the rule used is actually a combination of two more fundamental rules (i.e., Increase by Percentage and Moving Average, as defined more formally below) while the rates specified are the HEPI inflation index for the Increase by Percentage rule and $5.0 \%$ for the Moving Average rule. ${ }^{9}$ In the analysis that follows below, it is important to recognize that an endowment fund can change its spending policy by altering either the rule it uses or the rate that is applied within that rule.

For our purposes, two endowments will initially be considered to have comparable spending policies if those policies are based on the same spending rule. That is, funds that adopt a Moving Average payout rule based on, say, annual portfolio valuations over the previous three years will be classified in the same way regardless of what specific policy spending rate each fund applies to their respective average asset values. There are seven broad categories of spending rules used

\footnotetext{
${ }^{8}$ Two additional economic actors are represented in the exhibit: Consultants, who can provide guidance to either the Board or the Staff on a variety of topics, and Portfolio Sub-Managers, who the Staff may select to manage part or all of the endowment's assets. This "external manager" model (i.e., in which Staff selects investment managers from outside the endowment organization to construct asset class-specific security portfolios) is an increasingly popular format in practice and the role of the Consultant is often to advise the Board or Staff on which sub-managers to select. Walda and Griswold (2011) report that $80.0 \%$ of the endowments surveyed in 2010 employed an external consultant and $85.0 \%$ of those endowments using a consultant did so to advise them on the manager selection process.

${ }^{9}$ It is interesting to note that NACUBO reported that the actual payout rate for the Texas Christian University endowment fund for the 2007 fiscal year was $4.6 \%$ (expressed as a percentage of beginning-of-period fund assets). This indicates that there often can be a measurable difference between the ex ante policy payout rate and the $e x$ post actual payout rate, particularly when Moving Average spending rules that combine several past asset values are used.
} 
in practice, which in turn represent aggregated versions of 20 more detailed sub-classes. ${ }^{10}$ While the Appendix lists a more complete description of this spending rule taxonomy, the seven broad payout policy categories are given here as:

1. Decide on an Appropriate Rate Annually: Determines the spending rate deemed appropriate on a yearly basis.

2. Increase Prior Year's Spending by a Percentage: Adjusts spending upwards each year, using either a simple formula or one based on the inflation rate.

3. Spend a Percentage of a Moving Average of Market Values: Determines annual payout as a percentage of an average of beginning-of-period market values over a pre-specified series of past periods.

4. Spend a Percentage of Current Yield: Spend a percentage of current income generated during the investment period.

5. Spend a Percentage of Assets Under Management (AUM): Determines annual payout as a percentage the beginning-of-period fund assets for the current period.

6. Hybrid Rules: Uses a simple formula to combine two or more different payout categories into a single spending rule.

7. Other Payout Rules: Uses a formula or approach that differs from those listed above or did not provide a complete set of information.

Thus, the TCU endowment fund from the previous example would be classified as following a Hybrid Rule (i.e., Category 6), which itself is a combination of Category 2 (i.e., Increase Prior Spending by Percentage) and Category 3 (i.e., Moving Average).

At a broad level, these spending rule categories can be differentiated by the nature of the dollar payout amount they produce. Clearly, the Decide Annually rule is the most flexible in that it allows the Board to determine the exact amount of payout it wants to extract from the portfolio each year. Of course, this maximizes the tension on the Board in managing the trade-off between spending in the present versus preserving the endowment's value for future generations, particularly since UPMIFA removes the onus of making decisions that lead to an underwater fund. On the other hand, the Increase by Percentage rule makes the payout level

\footnotetext{
${ }^{10}$ This spending rule classification system was created after a comprehensive analysis of the series of annual NACUBO surveys, which began collecting this information in 2003. It differs somewhat from other classification schemes (e.g., Lapovsky (2009), Blume (2010)) primarily because the way in which NACUBO has reported spending rule data has evolved over time, particularly after Commonfund became involved in the reporting process in 2009. We provide a more complete discussion of the the data acquisition process in Section 3.
} 
exactly predictable and preserves the real spending level of the institution when the policy payout rate is tied to an inflation index. However, in years when asset values are falling, an Increase by Percentage rule will exacerbate the decline in the endowment portfolio's value. By contrast, a Percentage of AUM rule adjusts the payout to changes in the portfolio's beginning-of-year value, which has the effect of making the dollar payout level extremely volatile in financial markets that are themselves volatile. Moving Average rules attempt to mitigate this volatility by smoothing out the portfolio value to which the payout rate is tied, whereas Percentage of Yield rules are intended to set a payout that will not diminish the value of the endowment portfolio, which may be a factor that the Board of a fund that is already underwater might need to take into account. Finally, Hybrid rules, which often combine Moving Average and Increase by Percentage Inflation rules, seek a middle ground between predictable dollar payout and the preservation of the endowment's market value.

\subsection{Endowment Investment Policy}

Beyond setting the organization's spending policy, Figure 1 also highlights the role that the endowment fund's Board plays in determining the direction of its investment operation. As summarized in the endowment's investment policy statement, the primary function of the Board in this regard is two-fold: (i) to select the permissable asset classes that define the endowment's allowable investable universe; and (ii) to specify the target investment levels (i.e., weights) for each of these asset classes. Collectively, these two decisions represent the fund's strategic asset allocation policy, which is widely acknowledged to be the single most important decision that an organization makes to increase the value of its investment portfolio over time; see, for example, Brinson, Hood, and Beebower (1986), and Ibbotson and Kaplan (2000). Further, Acharya and Dimson (2007) note that most endowment funds use a strategic allocation approach to arrive at their policy portfolios due largely to the long-term nature of the investment problem they face. $^{11}$

Of course, a crucial aspect underlying the Board's strategic allocation judgment is the perceived level of risk tolerance characterizing the organization. Like mutual funds, endowment fund assets are most often managed without a "safety net", such as that provided for pension plans by the plan sponsor's balance sheet or the Pension Benefit Guarantee Corporation. In

\footnotetext{
${ }^{11}$ Typically, investment policy statements contain two additional features that are the responsibility of the Board: (i) the permissible tactical ranges for the extent to which asset class-level investments can differ from their strategic target weights; and (ii) the portfolios or indexes that represent the benchmarks for each asset class (e.g., the S\&P 500 index for U.S. public equity), which are used primarily for measuring the performance of the managed portfolio.
} 
this sense, endowment funds are often regarded as having risk tolerance similar to that of a taxexempt wealthy individual investor, although Black (1976) argues that endowment funds generally require less diversification in their asset portfolios than do otherwise comparable individuals. However, this appears to be a notion that has fallen out of favor, as the so-called endowment model approach to investing prevalent today is grounded on the principle that a wide variety of both traditional (e.g., public fixed-income and equity securities) and non-traditional (e.g., hedge funds, private equity) asset classes should form the investable universe; see Leibowitz, Bova, and Hammond (2010). Finally, endowment funds generally face the widest variety of investment restrictions, most of which are institution-specific since there is comparatively little regulation in this industry. ${ }^{12}$ This suggests that, as an institutional class, endowment funds might have considerable range in their investment policies and thus represent a setting in which the manipulation of allocation strategies might be able to add substantial value to portfolio performance.

Given the strategic allocation policy set by the Board, Figure 1 shows that the responsibility for designing and maintaining the actual endowment portfolio falls to the Staff. A baseline (or passive) approach for this process would be to mimic the strategic allocation policy by investing in the permissible asset classes at exactly their target weights and replicating the contents of the benchmark indexes as closely as possible; this is what Leibowitz (2005) terms "beta grazing". Within the context of the investment policy, the Staff can also usually engage in active portfolio management (i.e., "alpha seeking") in either of two ways: (i) tactical asset allocation, in which deviations from strategic asset class weights are selected; and (ii) security selection, in which asset class-level security portfolios that differ from those in the respective benchmarks are held. ${ }^{13}$ In their analysis of the relationship between asset allocation and investment performance for university endowment funds, Brown, Garlappi, and Tiu (2010) find that while strategic policy portfolios are remarkably similar across their sample, actively managed endowments are able to generate significantly larger alphas than passively managing ones, largely through Staff's use of its security selection skills. Indeed, Swensen (2009) argues that the ability to make high-quality active management decisions is the most important factor that distinguishes two other similar institutional investors. Thus, both Board and Staff appear to play an important role in the development and execution of an endowment's investment policy.

\footnotetext{
${ }^{12}$ In fact, Hill (2006) implies that the largest and least restricted endowment funds essentially operate as hedge funds in their pursuit of superior risk-adjusted returns, an observation borne out by the recent experience at the Harvard Management Company.

${ }^{13}$ In addition to tactical range restrictions or restrictions on which securities can or cannot be held (e.g., no tobacco stocks), investment policy statements can also specify risk control measures at the aggregate portfolio level, such as tracking error limits.
} 


\section{Data and Descriptive Statistics}

\subsection{Data Description}

The primary source of information for the spending and investment practices of educational endowment funds comes from a database maintained by the National Association of College and University Business Officers (NACUBO), a service and advocacy organization formed in 1962 to represent college, university, and higher education service providers throughout the United States, Canada, and Puerto Rico. Since 1984, NACUBO has surveyed its members on topics ranging from asset allocation and investment performance to endowment expenditures and other fund flows to organizational design and governance issues and then publishes a summary of that information in its annual Study of Endowments. ${ }^{14}$ Arguably, this survey represents the most comprehensive published source of data on college and university endowments anywhere in the world. Although the underlying data is self-reported by the member institutions, the study is free of survivorship bias as any college that could eventually have gone bankrupt but participated in the survey in the early years is retained in the database (see Brown, Goetzmann, Ibbotson, and Ross (1992)). Indeed, the large cross section of colleges represented in the survey suggests that there is little self-selection bias. Furthermore, the study does not backfill data; that is, a college can only fill out the survey for the current year and not for previous years in which no information was originally provided.

For the analysis that follows, we have obtained access to the survey data for fiscal years from 1984 to $2011 .^{15}$ For the purpose of our study, easily the richest part of the NACUBO database involves endowment investment practices. Specifically, information for some data items - such as the AUM for a particular fund, the annual investment return (net of fees) that it producedis available from the inception of the surveys in 1984. However, while aggregated sample-wide data on asset allocation patterns are available from 1984, fund-specific asset allocation data (i.e., where it is possible to match each endowment with its actual asset class investment weights during the investment period) was only obtainable starting with the 1989 survey. Given the number of partners involved in producing the annual surveys for NACUBO, it is not surprising that the asset classes definitions have been modified three times during the 1989-2011 sample period, most recently in 2009 with Commonfund's administration of the surveys. To maintain

\footnotetext{
${ }^{14}$ Since 2009, Commonfund has administered the survey process and jointly authored the studies with NACUBO. Before the current arrangement, other NACUBO partners involved in producing the annual surveys included TIAA-CREF (2000-2008) and Cambridge Associates (1988 to 1999); the NACUBO Investment Committee generated the surveys prior to 1988.

${ }^{15}$ To match the academic calendar, the fiscal year for an endowment typically ends on June 30. So, the NACUBO survey for 2011 covers the period from July 1, 2010 through June 30, 2011.
} 
consistency with the most recent reporting standards, we adopt the following ten different asset classes: U.S. Public Equity, Non-U.S. Public Equity, Fixed-Income, Real Estate, Hedge Funds, Venture Capital, Private Equity, Natural Resources, Cash, and Other Assets. All of the asset allocation data dating to 1989 has been adjusted, where necessary, to correspond to these asset class definitions. ${ }^{16}$

Unfortunately, information on spending practices in the endowment sample does not extend as far back as does the investment data. NACUBO began reporting the actual annual payout rate associated with a fund in 1994. This actual payout rate statistic is calculated as the total dollar amount of the payment from the endowment to the institution during a given fiscal year as a percentage of market value (i.e., AUM) of the portfolio at the beginning of the fiscal year. More specific information regarding the spending policy-both spending rule and policy rate - for every fund did not appear until the 2003 survey, meaning that we are able to trace the evolution of this aspect of the endowment management process (as well as the link between spending and investment practices) over the 2003-2011 period. Further, the categories defining the spending rule classifications were modified once during this time frame (i.e., when Commonfund got involved in the effort in 2009). Consequently, the seven spending rule categories listed in previous section were defined with sufficient breadth to allow for the proper placement of all 20 of the sub-categories used throughout the nine years for which this data was reported, as indicated in the Appendix. Finally, recognize that not every endowment self-reported spending policy data in each year for which they participated in the survey in other ways (e.g., reported asset allocation and investment performance results). As explained in more detail below, we assume the conservative posture that such omissions, when they occur, indicate that the endowment did not change its spending policy from the last reporting date.

\subsection{Endowment Summary Statistics: Fund Size, Returns, and Payout Rates}

Table 1 provides a broad overview of the number and size, investment performance, and spending practices for our sample of endowment funds. Specifically, the display reports on a yearly basis summary statistics for three different variables: (i) assets under management (AUM), measured as the market value of the total assets held in a fund as of the end of the respective reporting year; (ii) the overall investment return, reported net of all relevant fees; and (iii) the payout rate, which is defined as the actual dollar level of spending during the year in question expressed

\footnotetext{
${ }^{16}$ For example, from 2001 to 2008, NACUBO reported twelve asset class categories by accounting for Fixed Income in two sub-categories (i.e., U.S. and Non-U.S.) and similarly listing Real Estate in its public (i.e., REITS) and private forms.
} 
as a percentage of the beginning-of-period AUM of the fund. For all three of these statistics, the table lists the mean, median, minimum and maximum values, and standard deviations for each of the annual cross sections.

The first thing to note from Table 1 is that the number of institutions surveyed by NACUBO quadrupled (i.e., from 200 to 803) from 1984 to 2011 and that there was a roughly sixteenfold increase in the aggregate level of assets managed in the industry (i.e., from $\$ 25.4$ billion to $\$ 408.0$ billion) during that time. By contrast, the level of AUM for both the mean and median endowment increased only four-fold over the sample period-from $\$ 127.0$ million to $\$ 508.1$ million, on average - which represents a relatively modest compound annual growth rate in net-of-payout assets of $5.3 \%$, especially given that none of the amounts listed have been adjusted for inflation. However, the remaining AUM data reported in the exhibit indicate that focusing on the behavior of the "average" endowment may provide a poor representation of the entire universe. For example, the difference between the largest and smallest funds reported annually (e.g., $\$ 31.7$ billion versus $\$ 0.6$ million in 2011 ) shows the tremendous cross-sectional heterogeneity in the sample and suggests that endowments of different sizes may face very different asset management problems.

There are two other ways in which the reported statistics for fund investment performance and payouts suggest that the endowment universe is extremely varied. First, while the annual distributions of the overall fund returns do not appear to be highly skewed (e.g., there is not a large discrepancy between the mean and median returns reported for most years), the difference between the best and worst performing funds is considerable. ${ }^{17}$ For instance, while the mean fund returned $9.2 \%$ in 2005, the minimum and maximum returns for the 711 participating endowments were $-11.4 \%$ and $22.2 \%$, respectively. The indicative range of performance for this particular year was by no means abnormally large; if anything, it is less pronounced than the most dramatic years in the sample (e.g., 1989, 2000, 2007-2009). While there are several factors that might explain these different investment outcomes, such as portfolio risk levels or manager-specific skills, they nevertheless underscore our earlier point regarding the diversity of the objectives, constraints, and characteristics that represent these institutions.

The final way in which college endowments can be differentiated with these data is by the amount of their annual spending needs. The last five columns in the exhibit summarize the annual distributions of the actual dollar expenditures (as a percent of AUM) paid out by the

\footnotetext{
${ }^{17}$ The return data shown in Table 1 are net of fund expenses, but they are not adjusted for risk. A more thorough analysis of the nature and sources of risk-adjusted performance across a comparable sample of endowment funds can be found in Brown and Tiu (2010).
} 
funds. The average annual value for this payout rate is about $4.8 \%$, which did not appear to change much from one year to the next during the sample period. However, this relative constancy in the average value masks a considerable degree of cross-sectional variation in actual payouts rates, where the spread of values in a given year ranges from zero to $85.0 \%$. Further, as indicated by both the cross-sectional standard deviations and difference between the minimum and maximum values, the sample-wide variation in payout rates appears to have increased substantially after 2008. In fact, this highly variable pattern of endowment spending over time is consistent with that reported by Nettleton (1987) for the pre-1985 period. In the present context, the important point to consider is that fund spending policies may be linked to the risk tolerance of the endowment and, as a consequence, should be related to the allocation decision and ultimate investment performance, as suggested by Dybvig (1999). ${ }^{18}$

\subsection{Endowment Summary Statistics: Asset Allocation}

Table 2 lists the actual percentage allocations by the endowment fund universe to each of the ten NACUBO asset classes in use as of the 2011 survey date: U.S. Public Equity, Non-U.S. Public Equity, Fixed-Income, Real Estate, Hedge Funds, Venture Capital, Private Equity, Natural Resources, Cash, and Other Assets. The figures reported represent the equally weighted average annual values of the percentage of AUM allocated to a particular asset class using all of the participating funds in a given year starting in 1989. Viewed over time, there are several trends in these data that imply important shifts in the way endowment fund managers have approached the asset allocation process. First, the percentage invested in public equities (i.e., U.S. Equities and Non-U.S. Equities) has changed substantially over time, while remaining well below the level advocated by Thaler and Williamson (1994). Interestingly, this allocation both started and ended the sample period at just under $50 \%$, but maintained a level of $55 \%$ to $65 \%$ for the years between 1996 and 2007. Further, the composition of this allocation has changed dramatically over the entire period, with non-U.S. equities experiencing a substantial increase (e.g., from $1.7 \%$ in 1989 to $17.0 \%$ in 2011) while U.S. equities declined significantly (e.g., from $47.0 \%$ to $31.7 \%$ ). Allocations to the traditional fixed-income categories also declined dramatically during the sample period, from around $31.7 \%$ at the beginning of the sample period to just $19.3 \%$ in 2011.

\footnotetext{
${ }^{18}$ In an interesting extension of this point, Dimmock (2012) conducted a cross-sectional analysis of endowment fund allocation patterns during the year 2003 and concluded that factors such as the riskiness of a university's non-financial income, cost structure and credit constraints can also affect its investment decision-making and performance.
} 
It is the Alternative Asset classes - typically defined by endowment funds to include hedge funds, non-public equity positions (both Venture Capital and Private Equity (i.e., buyout) investments), real estate, and natural resources - that benefitted the most from the decreased allocation to traditional fixed-income products. Some of these allocation gains were modest, such as the increases from $0.6 \%$ to $1.3 \%$ for venture capital investments or from $3.0 \%$ to $3.4 \%$ in real estate. ${ }^{19}$ Clearly, then, the biggest beneficiary of the increased pattern of "alternatives" investing occurred in the Hedge Fund category, which represented just under $13.0 \%$ of the AUM of the average endowment fund by 2011, placing them in size just below the average dollar investment in non-U.S. equity securities. Given that the first hedge fund allocation did show up in the data until 1990, this represents a truly significant shift in the investment approach adopted by endowment managers. To underscore this point, we also computed a more complete crosssectional analysis of the annual asset allocation samples, including the median, maximum, and minimum values as well as the standard deviation of the distribution. Although not reported in Table 2, these additional statistics are nevertheless useful in understanding the diversity in the investment commitment to hedge funds across the endowment universe. For instance, in 2005, the minimum allocation was $0.0 \%$ while the maximum allocation was a $82.1 \%$ ! Clearly, different endowments have very different strategies concerning alternative assets.

A significant factor related to these different asset allocation patterns is the size of the endowment fund. Simply put, larger funds invest assets in a very different fashion than do smaller funds. This is phenomenon is illustrated in Figure 2, which provides snapshots of endowment investments at different points of time and for funds of different size. To generate these comparisons, we separated the fund sample into quartiles based on beginning-of-period AUM for each year in the sample period. We then calculated mean asset allocation percentages for each quartile as an equally weighted average within the sub-sample, rebalancing those stratifications on a yearly basis. Further, for comparative ease, we consolidated the asset classes into four broader categories: Public Equity (U.S. and Non-U.S.), Fixed Income, Alternatives (Real Estate, Hedge Funds, Venture Capital and Private Equity, Natural Resources), and Cash \& Other Assets. Panel A of the display compares these aggregated allocation percentages across AUM

\footnotetext{
${ }^{19}$ Recall that beginning in 2009, NACUBO collapsed two Real Estate asset classes-Public (i.e., REITS) and Private - into a single category, moving the REIT allocation to U.S. Public Equity. Consequently, to insure comparability with the reported allocation data from 1989 to 2008, we have added (subtracted) $1.20 \%$ to the Real Estate (U.S. Public Equity) asset class for the years 2009 to 2011. This percentage represents the average REIT allocation for the five-year period ending in 2008.
} 
quartiles at the beginning and end of the sample period, while Panel B compares how those allocation patterns evolved over time for the largest (Q4) and smallest (Q1) size quartiles. ${ }^{20}$

As both panels of the exhibit help make clear, while there were significant differences across asset classes, there were relatively small differences in asset allocations patterns across endowments of different size at the beginning of the sample period (e.g., investments in Alternatives in 1989 were $3.9 \%$ and $6.5 \%$ for quartiles Q1 and Q4, respectively). However, this situation changed dramatically by 2011, when Alternatives investing for the largest fund quartile rose to $45.0 \%$ while the Alternatives allocation for the smallest funds remained relative low at $9.6 \%$. To finance this increased allocation to Alternatives, the average Q4 endowment reduced its allocation to both Public Equity (50.7\% in 1989 to $37.6 \%$ in 2011) and Fixed Income (29.5\% to 12.2\%). Conversely, the smallest endowments actually increased their Public Equity investments over this period (44.9\% in 1989 to $56.2 \%$ in 2011) primarily by reducing their Cash allocation, whereas their Fixed Income allocation remained relatively stable (32.2\% to $26.3 \%)$. Thus, it is reasonable to conclude that the overall trend toward an increased allocation to Alternatives at the expense of Public Equity and Fixed Income we noted earlier is predominantly the result of actions taken by the managers of the largest endowments.

\subsection{Endowment Summary Statistics: Spending Rules}

As discussed above, the annual NACUBO surveys have included details of the spending rules used by their sample of educational endowments since the 2003 fiscal year. For each yearly report between 2003 and 2011, we analyzed the stated rule for every available fund and placed it into one of the 20 specific sub-categories - which, in turn, led to its placement into one of the seven broader categories - described in the Appendix. Table 3 summarizes these classifications, reporting for each year the following statistics: total number of sample endowments; percentage frequency of rule use; mean (median) actual payout, as a percentage of AUM; mean (median) AUM; mean (median) annual investment return; and mean (median) standard deviation of the policy (i.e., benchmark) portfolio corresponding to funds in that spending rule class. ${ }^{21}$ Further, starting with the fiscal year 2009, the spending rule portion of the NACUBO survey was ex-

\footnotetext{
${ }^{20}$ To conserve space, Figure 2 compares asset allocations for the various sub-samples of the endowment universe for just two years: 1989 and 2011. It should be noted that data for the omitted years do not change our conclusions about how endowment allocation patterns have changed over time; we have produced a complete set of annual findings for the entire 1989-2011 sample period and these results are available upon request.

${ }^{21}$ More precisely, this volatility statistic was calculated as follows: First, for each fund in a given survey year and rule class, we observed their asset allocation weights. Second, time-series return data for the benchmark indexes associated with each asset class (which are described in detail in Section 6), we calculate a sample asset class variance-covariance matrix. Finally, a policy standard deviation statistic was then calculated for each fund as the square root of the product of its investment weights and the variance-covariance matrix; the exhibit lists the mean (median) of these values within each rule category.
} 
panded to include additional information regarding the relationship between endowment payout amounts and the institution's budget, as well as the funding status of the portfolio. Consequently, for the years 2009-2011, we also report summary statistics for: mean (median) payout as percentage of budget; the mean number of endowments that impose a special spending appropriation (i.e., temporary expenditures in addition to the stated permanent policy); and the percentage of funds that are "underwater" (i.e., has a current market value that is less than its original level).

Perhaps the most intriguing finding shown in the display is the sizeable fraction of endowment funds that base their spending policies on some form of a moving average of past portfolio values, which is intended to smooth out year-to-year variations in the dollar level of the portfolio payout. Looking at each of the annual samples, the fraction of funds using a Moving Average rule ranges ranges from a low of about two-thirds (65.4\% in 2010) to three-quarters $(75.6 \%$ in 2008). By contrast, the second most frequently used spending rule - the Decide Annually category - is also the most flexible in the payout amount it allows from one period to the next and accounts for as much as $10.6 \%$ of funds in 2011 and as few as $4.9 \%$ in $2008 .{ }^{22}$ The remaining five categoriesIncrease by Percentage, Percentage of Yield, Percentage of AUM, and Hybrid - are roughly equally distributed, with each accounting for 3.5-5.5\%, on average, over the nine years for which this data has been collected.

Of course, an interesting question implicit in these reported frequencies is what motivates a given endowment to select one spending rule over another? Table 3 provides some useful indications of how funds differ by spending rule choice. In particular, notice that in each of the yearly cross sections there is considerable variation in the average percentage payout generated by the various rules (e.g., 3.4 to $5.1 \%$ in 2010 , 4.6 to $5.6 \%$ in 2003). Generally speaking, it appears that the Increase by Percentage and Hybrid rules are associated with the largest average payout percentage, while the Percentage of Yield rule produces the smallest payout. Further, judging from the data reported over the most recent three years in the sample, it also appears that those endowments responsible for producing a larger percentage of the institution's budget select a Hybrid or Increase by Percentage rule (e.g., 2011 mean payout-as-percentage-of-budget statistics of $18.2 \%$ and $17.0 \%$, respectively), whereas endowments with payouts that are a significantly smaller percentage of their institution's budgets seem to gravitate toward Moving Average or

\footnotetext{
${ }^{22}$ To underscore this "smoothing vs. flexibility" comparison, notice that in 2009 (i.e., the fiscal year incorporating the financial market decline of late 2008, 36.1\% of the endowments using the Decide Annually rule were underwater, compared to just $22.1 \%$ using Moving Average rules. By 2011, the economic recovery that took place during the preceding two years had reduced the frequency of underwater funds in these two categories to be virtually the same (i.e., $5.5 \%$ and $4.9 \%$, respectively).
} 
Percentage of Yield rules (e.g., 8.3\% and 7.6\%, respectively, in 2011). Given that funds using Hybrid rules need to produce more of the institution's total budget, it is not surprising to see that these endowments also tend to have special appropriation frequencies that are among the highest for any rule class (e.g., 25.9\% and 31.9\% in 2011 and 2010, respectively).

These summary statistics also contain an indication that an endowment's spending rule and its investment performance may be connected, albeit it in a surprising fashion. From the mean policy volatility statistics reported for each of the spending rule categories in the nine annual cross sections, it is apparent that endowment funds seem to target similar levels of benchmark risk exposure regardless of what other differences they might have. This fact, which was first noted by Brown, Garlappi, and Tiu (2010), can best be seen by the remarkably narrow ranges for the volatility measures in any given year (e.g., $9.3 \%$ to $9.9 \%$ in $2010,9.6 \%$ to $10.1 \%$ in 2008 ). On the other hand, while these comparable "risk budgets" sometimes lead to a similarly narrow range of realized investment returns (e.g., mean annual returns of $11.5 \%$ to $12.5 \%$ in 2010 ), the dispersion in actual investment performance often varied far more widely across spending rule groups than differences in the policy risk levels would imply (e.g., $-5.0 \%$ to $-1.0 \%$ in 2008).

Given the relative importance of the Moving Average spending rule in practice, Table 4 provides an additional breakdown of this classification by the various valuation frequencies and time horizons that define it. The display lists summaries for fiscal years 2009, 2010, and 2011, the three annual samples for which Commonfund collected this more detailed data in the NACUBO surveys. The three frequency columns show that the vast majority of Moving Average rules in use are based on either quarterly or annual measures of past AUM values. Further, these two measurement frequencies are used in roughly comparable amounts, although there appears to have been a slight shift toward the quarterly averaging process (i.e., $33.5 \%$ to $39.9 \%$ useage from 2009 to 2011) and away from annual averaging. Beyond that, as indicated by the four time horizon columns, averaging the AUM base over a period between three to five years is easily the most popular single choice in all three cross sections, despite the fact that five-to-seven year averaging became more prevalent over the period (i.e., $11.9 \%$ useage in $2009,18.8 \%$ in 2011 ).

Finally, as with the asset allocation patterns discussed above, endowment size is also apparently a factor in determining the spending rule that is selected. For example, from Table 3, the mean AUM for funds in the Hybrid rule category in 2011 is $\$ 1,143.3$ million, compared to $\$ 756.9$ million and $\$ 326.8$ million mean portfolio values in the Decide Annually and Moving Average categories, respectively. To get a better sense of these size dynamics, we also calculated spending rule frequencies by fund size quartile, from the smallest (Q1) to the largest (Q4), for each of the 
nine annual samples. Panel A of Figure 3 illustrates these inter-quartile distributions at the two yearly end points of the sample while Panel B shows the rules used in quartiles Q4 and Q4 for three different years. In 2003, it is apparent that the smallest endowments used Moving Average rules to a lesser extent than larger funds, in favor of a relatively bigger use of Decide Annually and Percentage of AUM rules. However, by 2011, use of a pure Moving Average policy in the Q4 quartile had declined dramatically to the point that those funds had the lowest comparative frequency, with an increased use of Hybrid rules providing the offset. On the other hand, the use of Moving Average rules by Q1 funds remained much steadier over the same time frame. Thus, as with asset allocation changes over time, variations in spending rule use also appear to be driven primarily by the largest endowments in the sample, a topic we explore in more detail in the analysis that comes next.

\section{The Evolution of Spending Policies Over Time}

Having just established some important cross-sectional differences in spending rule adoption practices, it is also useful to consider the issue of how a given endowment fund's spending policy has changed (if at all) over time. In one sense, this is a more interesting question to address since, given the prediction of Merton (1993) in the context of the relatively static nature of the investment problem that most educational institutions face, it is not clear that there is any reason to expect an endowment to modify the fundamental way in which it views its spending mandate from one year to the next. On the other hand, recent research suggests that endowments do face changing circumstances in the form of unexpectedly adverse economic conditions (see Brown, Dimmock, Kang, and Weisbenner (2010)) or competition for resources with peer institutions (see Goetzmann and Oster (2012) and Lerner, Schoar, and Wang (2008)) that necessitate changing their spending policies on an occasional basis. However, there appears to be little in the way of a priori justification for a widespread frequency of changes to the nature of these statements. ${ }^{23}$

To analyze this issue, we examine how all of the endowment funds in the NACUBO sample specified their spending policies during every year between 2003 and 2011. Formally, for each Endowment E, we examine its spending policy (i.e., both spending rule and policy rate) for every Year $\mathrm{T}$ that it reported survey data and characterize its spending rule according to the taxonomy described earlier. Endowment E is considered to have changed its spending policy

\footnotetext{
${ }^{23}$ In this discussion, it is important to keep in mind the distinction between permanent spending needs, as defined by Tobin (1974), and temporary needs that might be driven by changing macroeconomic or institutionspecific factors. As documented in Table 3, roughly one in three endowments exercised its capacity to make special appropriations as necessary, which mitigates the need to change their formal spending policies to accommodate temporary changes in circumstances.
} 
if at least one of two conditions occur: (i) the spending rule it uses in Year $\mathrm{T}+1$ falls into a different category than its spending rule in Year T (e.g., a switch from a Decide Annually rule in 2009 to a Hybrid rule in 2010); or (ii) a change from Year T to Year T+1 in the designated policy payout rate specified within the same spending rule (e.g., a switch from a commitment to spend $4.0 \%$ of a 12-quarter Moving Average of past portfolio values in 2005 to $5.0 \%$ of a similar Moving Average calculation in 2006). Notice that while an adjustment in either the spending rule or the designated rate applied within that rule is regarded as policy change, a modification in the former is considered to be a more extreme alteration of the way in which the endowment's investment problem is viewed. ${ }^{24}$

\subsection{Tabulating Spending Policy Changes on a Yearly Basis}

Table 5 documents at a broad level the extent to which endowments alter their spending policies from one year to the next. Panel A summarizes the frequency of change to any aspect of the spending policy (i.e., rule or rate) while Panel B isolates just those endowments that altered the nature of the spending rule to the extent that it switched categories in consecutive years. To interpret the exhibit, for the fiscal year 2009, there were 842 endowments that reported information about their spending policy in the annual survey. Of those, 749 also reported the details of their spending policy in the 2010 NACUBO survey, meaning that 93 endowments that reported spending data in 2009 did not report in the following year. ${ }^{25}$ Of those 749 endowments from the 2009 survey that also reported in the 2010 survey, 463 maintained their spending policies from one year to the next whereas 286 of those funds altered either their spending rule or their policy rate (Panel A). Consistent with our convention of treating non-reporting endowments as ones that did not modify their policies, we list the frequency of spending policy change as $33.97 \%(=286 / 842)$. Panel B then shows that of the 286 endowments that changed some aspect of their spending policies from 2009 to 2010, 131 of them actually altered their spending rule in a way that caused a change in classification. This is represented in the last column as a rule frequency change of $15.56 \%(=131 / 842) \cdot{ }^{26}$

\footnotetext{
${ }^{24}$ With this definition, an endowment that altered its spending rule from a three-year moving average based on an annual observation frequency to a five-year Moving Average based on a quarterly observation frequency would not be viewed as having made a policy change, assuming it also kept its designated payout rate the same. In this regard, the procedure we use for identifying spending policy changes that occurred in the sample is conservatively biased.

${ }^{25}$ An endowment might be listed at "Not Reported at $\mathrm{T}+1$ " either because it chose not to report data for that particular item (but otherwise participated in the survey) or because it dropped out of the survey altogether. To be conservative, in our calculations of the frequency of endowments that change their spending policy, we treat a non-reporting fund as one that did not change any aspect of its previous policy.

${ }^{26}$ Of course, both of these change frequencies would be larger if based on just those funds from the 2009 survey that also reported data in $2010 ; 38.18 \%(=286 / 749)$ and $17.49 \%(=131 / 749)$ for policy and rule changes, respectively.
} 
The clear and surprising implication from the findings in Table 5 is that endowment funds adjust their spending policies far more often than might be reasonably expected given the longterm nature of their investment mandates. Specifically, the data in Panel A show that annual frequencies with which either spending rules or policy payout rates (or both) are changed range from $8.95 \%$ (2006) to $36.43 \%$ (2005). The weighted mean (as a percentage of reporting funds) for these annual change frequencies is $24.62 \%$, meaning that, on average, one in four of the endowments in the sample altered its spending policy each year. Further, as summarized by Panel B, the percentage of endowments changing their actual spending rule - the most extreme policy adjustment they could make - in a given year ranged from $3.80 \%$ to $36.43 \%$, with a weighted mean annual change frequency of $18.35 \% .{ }^{27}$

Although theory (i.e., Merton (1993), Woglom (2003)) predicts that the expected number of spending policy changes in a given survey year is zero, it is difficult to say whether these change frequency patterns can be considered extremely abnormal absent more information of the how the investment problem faced by the sponsoring institutions might have changed. Nevertheless, testing the observed frequencies against two different prospective null hypotheses is instructive. First, assuming that $5.0 \%$ of the endowments will modify their spending mandates in a given year (i.e., a 1-in-20 event), the Pearson chi-squared statistics testing the goodness of fit between the observed and forecasted distributions for the spending policy and spending rule change samples are 6,350.46 and 3,843.25, respectively. Both of these statistics are statistically significant with p-values of less than 0.0001, indicating that endowments make adjustments far more frequently than might occur on a random basis if the true proportion of expected changes was zero. Beyond that, the respective chi-squared statistics testing whether the observed annual change frequencies equal the weighted mean frequencies (i.e., $24.62 \%$ for spending policy, $18.35 \%$ for spending rules only) are 269.45 and 413.38 , which are also statistically reliable at better than a 0.0001 level. Thus, it is also the case that the spending policy changes shown in Table 5 vary significantly from one another on a year-to-year basis.

Finally, as a supplement to this analysis of how frequently spending policies changed on annually, it is also useful to consider the total number of times during the 2003-2011 sample period that each endowment altered its stated spending rule. To tabulate this information, we focused on the 628 funds that reported their rules continuously over the entire set of nine surveys for which spending data was collected. As before, a fund was considered to have made a modification if the spending rules it reported in Year $\mathrm{T}$ and Year $\mathrm{T}+1$ fall into different

\footnotetext{
${ }^{27}$ Prior to the 2006 survey, NACUBO did not report separate data for policy payout rates. So, for 2003-2005, the change frequencies for the total spending policy are based solely on changes to the reported spending rules.
} 
categories, so that the maximum number of changes that could be observed for any Endowment $\mathrm{E}$ is eight. Figure 4 presents a histogram of these statistics. Exactly half (i.e., 314 of 628 ) of the funds did not adjust their spending rule at all during this interval, meaning that exactly half of the funds did make at least one formal adjustment. In fact, more endowments made two changes to their stated rule (129) than those that made only one modification (101). Further, $13.38 \%$ (84 of 628 ) changed this aspect of their spending policy three or more times and one endowment altered its spending rule in every one of the available surveys!

\subsection{Spending Rule Migration Patterns}

Given this unexpectedly large number of annual spending policy changes, a natural question to ask is which mandates are most likely to be abandoned and which are most likely to be subsequently adopted? Table 6 addresses this issue by focusing on the more narrow topic of spending rule migration trends. Specifically, for every Endowment E, we observed the spending rule it adopted for both Year $\mathrm{T}$ as well as in the following Year $\mathrm{T}+1$. Then, for each Year $\mathrm{T}$ spending rule classification, we tabulated which of the seven categories the same fund fit into in the next year. Notice that by this sorting process, we account for all possible outcomes for how a given Endowment E can modify its spending rule, including the fact that it might not change it at all.

Panel A reports these annual transition frequencies for all of the sample funds over the entire 2003-2001 time horizon. The first column lists the seven spending rule categories that endowments adopted in Year T. The remaining seven columns then summarize the spending rule category a given Endowment E fit into in Year $\mathrm{T}+1$. The data in the table have been scaled by dividing the number of raw observations in a particular cell by the total number of original Year T observations in that particular row. Thus, all of the entries represent the percentage of the funds using a certain rule at Year $\mathrm{T}$ that now fall under the respective Year $\mathrm{T}+1$ rule. For example, the first row of Panel A in Table 6 corresponds to those endowments that adopted the Decide Annually rule in Year T. Of those, $47.72 \%$ remained in the Decide Annually rule (i.e., did not change) during the following year, while $39.82 \%$ of those endowments switched their spending policy to a Moving Average rule. By construction, each of the rows in the display sums to $100.00 \% .^{28}$

\footnotetext{
${ }^{28}$ Notice also that this exhibit is constructed so that each endowment is likely to appear multiple times since a comparison of rules in place for Year $\mathrm{T}$ and Year $\mathrm{T}+1$ produces up to eight observations per fund over the nine-year time frame for which spending rule data was available. Of course, any fund that changed spending policies will see its data represented in different rows.
} 
Arguably the most interesting aspect of the reported findings is that the various spending rules have dramatically different likelihoods of being retained from one survey year to the next. The diagonal elements of the matrix (starting from the top left cell) indicate the percentage of a particular spending rule category that did not change (i.e., was retained) in the following period. Clearly, with $88.12 \%$ and $79.85 \%$ retention, respectively, the Moving Average and Hybrid rule categories are the only ones that have a better than three-in-four chance of remaining in place in consecutive years and are therefore the only rules whose adoption appears to be stable. Conversely, the retention rate for Percentage of Yield rules is just 35.74\%, meaning that approximately two out of three funds that adopted that mandate in Year $\mathrm{T}$ formally altered their spending policies within the next twelve months.

It is also useful to consider which spending rules are the most likely to be adopted, once an endowment decides to modify its current policy. This information can be inferred by looking down the last seven columns displayed in Panel A. Given the previous findings, it is not surprising that Moving Average rules appear to be the most popular destination to which the other six spending rules migrate; for instance, in addition to the $39.82 \%$ change from Decide Annually rules noted above, Moving Average rules are also adopted by $36.55 \%$ of funds changing from Percentage of Yield rules, by $35.25 \%$ of funds altering Other rules, and by $34.29 \%$ of funds altering Percentage of AUM rules. By inspection, no other single rule category even comes close to matching this migration pattern. In contrast, Hybrid rules, which was the only category besides Moving Average rules that was able to retain more than three-quarters of its adopters in a given year, was not able to attract as much of $4.00 \%$ of the annual migration from the other spending rules. This suggests that Hybrid rules represent a highly fund-specific form of spending policy that is likely to be stable once adopted, but unlikely to be the destination for the typical endowment seeking to alter its payout rules.

The last two panels in Table 6 extend this analysis by focusing on the behavior in different sub-divisions of the sample. Panel B reproduces the spending rule migration patterns just described for two different sample periods straddling the global economic downturn that began in the fall of 2008: (i) 2003-2008, and (ii) 2009-2011. ${ }^{29}$ Panel C then reproduces these findings over the entire sample period for funds in the largest (Q4) and smallest (Q1) AUM quartiles as of a particular Year T. The most striking feature of these transition matrices before and after the 2008 financial market downturn is the marked increase in the probability that endowments retain

\footnotetext{
${ }^{29}$ Recall the convention in the educational endowment industry to designate fiscal years that end on June 30. Thus, the 2009 fiscal year began on July 1, 2008 (i.e., before the putative start of the crisis) and ended on June 30,2009 .
} 
their previous spending rules. As shown in diagonal entries in the upper and lower portions of Panel B, all seven of the rule categories show higher retention frequencies in the 2009-2011 subperiod than they did in 2003-2008 time frame. For some of these rule classes (e.g., Increase by Percentage: $48.39 \%$ to $80.85 \%$, Percentage of Yield: $30.35 \%$ to $58.33 \%$ ), the change in retention frequency is quite dramatic. On the surface, this appears to be a curious outcome; the findings of Brown, Dimmock, Kang, and Weisbenner (2010), in fact, would suggest that adverse economic environments might induce more policy adjustments than fewer. However, one explanation for this increased reluctance for endowments to alter their spending rules in the two years following the market downturn is that, as a result of steep declines in AUM, the gap between the required spending dollars and projected dollars using any rule was so extreme that any adjustment to the permanent policy guidelines would not have solved the problem. Instead, many endowments relied on temporary measures to close this spending gap; for instance, the summary statistics in Table 3 show that about one out of every three endowments invoked special appropriations in the 2009, 2010 and 2011 fiscal years. Thus, consistent with the notion that the spending rule policy statement represents a vision of the long-term investment problem faced by the institution, Boards tend to respond to extreme events of a temporary nature with solutions that are similarly short-lived.

The transition matrices for the largest and smallest fund size quartiles shown in Panel $\mathrm{C}$ of Table 6 also indicate significant cross-sectional differences in the way endowments with disparate AUM levels alter their spending policies. While the values reported for the various cells appear to be more erratic than those shown in Panel B, due to the small frequencies associated the sample quartiles, they nevertheless indicate some similarities and disparities. First, the retention rate for Moving Average rules was extremely high for both large (87.06\%) and small $(91.22 \%)$ endowments and the migration into this rule category (i.e., the data in the respective MovingAverage ${ }_{T+1}$ columns) occurred for both size quartiles with about the same frequency. Conversely, the retention rate in the large funds for Hybrid rules was virtually $100.00 \%$, indicating that the biggest endowments adopting this spending policy category essentially never change. For small endowments, however, the loyalty to Hybrid rules was far more suspect (47.83\% retention), meaning that more Q1 endowments switched away from Hybrid rules than kept them from one year to the next. For these funds, it was almost as probable (39.13\%) that they would modify the spending rule by changing to a simpler Moving Average formula-which is likely to have been one of the rule categories combined in the Hybrid approach - than retain the previous combination rule. Finally, notice that no small funds switched to an Increase by Percentage 
rule - and only $50.00 \%$ of previous adopters retained that policy — over the entire sample period and that no large funds retained an exclusive reliance on a Percentage of Yield rule.

\section{$5 \quad$ The Determinants of Spending Rule Changes}

The preceding results leave little doubt that, collectively, university endowment funds alter their formal spending policies far more frequently than might be expected. However, beyond some suggestions from the reported data that patterns in these rule and payout rate changes are linked to some cross-sectional and temporal differences in the sample, it is not clear what the determinants of spending policy modifications actually are. In this section, we address that question by examining the formal links between a measure summarizing these changes and several variables observable in advance of a period in which an endowment either did or did not adjust its spending rules.

\subsection{Defining Potential Determinants}

In the statistical analysis that follows, we begin by defining the dependent variable $\left(P O L C H G_{T+1}\right)$ as an indicator variable assuming the value of 1 if Endowment E changed its stated spending rule between the survey years $\mathrm{T}$ and $\mathrm{T}+1$, and 0 otherwise. Accordingly, each of the potential explanatory factors that we consider are observable as of Year T. The following discussion describes these regressors, including how each of them is defined as well as the direction of the predicted influence they have on $P O L C H G$.

The findings discussed in Section 3.4 revealed a potential connection between an endowment's spending policy decision the nature of the returns produced by its investment portfolio. Although the ranges in the mean levels of portfolio return and policy volatility reported in Table 3 for the seven spending rule categories were fairly narrow, it is nevertheless a reasonable conjecture that both the amount and stability of the change in the fund's market value could influence the institution's decision to alter its payout formula. We therefore define as potential determinants the endowment portfolio's Year T investment return $\left(R E T_{T}\right)$ and policy portfolio volatility level $\left(V O L_{T}\right)$, as described earlier. The relationship between POLCHG and $V O L$ should be positive: the less predictable the portfolio's asset value is, the more likely the endowment might have to alter its spending plan. Conversely, positive investment returns in a given fiscal year should 
make it less likely that the endowment will need to adjust its long-term policy, leading to a negative predicted relationship between $R E T$ and $P L C H G{ }^{30}$

Two other variables that were shown earlier to be connected to an endowment's choice of spending policy are the level of its actual payout and the size of its investment portfolio. The Year T values of these factors - which we label as $P A Y O U T_{T}$ and $L O G A U M_{T}$, respectivelyare also included as potential determinants in the analysis reported below. As shown in Table 3, funds with higher (lower) payout rates were more likely to use Increase by Percentage or Hybrid (Percentage of Yield) rules over the sample period. Thus, the relationship between PAYOUT and $P O L C H G$ is likely to be negative in that funds with higher required payouts are likely to have already adopted the rules that best serve that purpose. On the other hand, it is not clear what impact the market value of the endowment portfolio, which for scaling purposes is expressed here as the natural logarithm of the fund's AUM, might have on POLCHG. The data summarized in Figure 2 shows that the largest funds have been far more willing and able to adjust their asset allocations than smaller endowments, which might suggest that they are also less likely to need to adjust their spending policy definition in changing economic environments, implying a negative relationship. However, as indicated by Figure 3, it is also the case that large endowments appear to change their spending rules more frequently, perhaps because their organizational mobility permits making quick adjustments to all of their various operating policies.

It is possible that spending rule changes are also linked to the specific nature of an endowment's asset allocation decision. In particular, it was also shown in Section 3.3 that endowments vary considerably in the use of alternative assets and these investments are especially critical to determining both the absolute and risk-adjusted returns that an institutionally managed portfolio produces (see Lerner, Schoar, and Wongsunwai (2007) and Brown, Garlappi, and Tiu (2010)). Thus, as described earlier, we define $A L T I N V_{T}$ as the percentage of an endowment's Year $\mathrm{T}$ portfolio that is invested in the hedge fund, private equity, real estate, and natural resources asset classes. The effect of ALTINV on POLCHG could go in either direction; the fact that larger allocations to alternatives might produce higher returns could generate the negative correlation hypothesized above for RET, but the greater degree of illiquidity associated with the alternative asset classes could create less investment policy flexibility, which in turn could lead to a higher likelihood of modifications to the spending policy.

\footnotetext{
${ }^{30}$ The negative forecasted connection between RET and POLCHG might be better seen from the other direction. That is, negative portfolio returns might cause a spending policy change-perhaps in addition to the special appropriations discussed earlier - because the income generated by the portfolio, as well as the fund's reduced AUM level, is not sufficient to generate the required expenditures under the old policy.
} 
Returns to the investment portfolio are not the only way that an endowment can fund its spending needs. Educational institutions routinely receive donations from a variety of public and private supporters that can either be used to increase the size of the current portfolio or be earmarked for direct expenditure (see Brown, Dimmock, and Weisbenner (2012)). In either case, we posit that larger levels of these supplemental contributions would make it less likely that an endowment would have to modify its spending rule to meet its budgetary needs, implying a negative relationship between Year T donations (labeled as $D O N A T E_{T}$ ) and future POLCHG. The NACUBO database does not contain observations on donations directly, but these contributions can be inferred for a given fund by taking the difference between the portfolio's value at the end and beginning of the period, adjusted for the returns earned during the period, plus the payout amount. That is, expressed as a percentage of assets, we have

$$
D O N A T E_{T}=\left[A U M_{T+1}-A U M_{T} X\left(1+R E T_{T}\right)\right] / A U M_{T}+P A Y O U T_{T},
$$

where the AUM levels are expressed as beginning-of-period asset values.

Finally, the descriptive data in Table 3 also strongly indicated that both the percentage of the institution's overall budget that the endowment was responsible for delivering as well as its ability to make special payout appropriations were linked to the choice of permanent spending rule. We therefore allow for the possibility that the Year $\mathrm{T}$ value of the budget variable (defined earlier as the actual payout in Year T divided by the school's budget over the same period and labeled here as $\left.P C T B D G T_{T}\right)$ and a variable indicating whether a special appropriation was made in Year T (labeled as $A P P R O P_{T}$ ) help to explain future $P O L C H G$. We posit a positive relationship between $P C T B D G T$ and $P O L C H G$ if, ceteris paribus, a fund obligated to deliver a bigger proportion of the university's spending needs must stand ready to alter its payout rules to do so in changing economic conditions. Conversely, consistent with the results in Table 6 , the use of temporary appropriations should make formal spending rule changes less likely, leading to a negative relationship between $A P P R O P$ and $P O L C H G$. A challenge to testing either of these hypotheses, however, is that NACUBO only reports data for PCTBDGT and APPROP beginning with their 2009 survey, leaving only three yearly observations.

\subsection{Statistical Analysis}

Given the dichotomous nature of our spending rule change dependent variable, we examined the statistical relationship between $P O L C H G$ and the various prospective determinants using 
a series of probit regression models that represent variations of the following functional form:

$$
Z_{T+1}=f\left(R E T_{T}, P A Y O U T_{T}, L O G A U M_{T}, A L T I N V_{T}, D O N A T E_{T}, V O L_{T}\right)+\epsilon_{T+1}
$$

where $Z_{T+1}$ represents an unobservable, continuously distributed index variable related to POLCHG $G_{T+1}$. Because of the well-known statistical challenges inherent in working with panel data (e.g., a time series of cross-sectional observations), we estimate (2) as a linear model using three different approaches: (i) a full panel data regression with Year fixed effects only; (ii) a full panel data regression with both Year and Fund fixed effects; and (iii) the multi-stage approach of Fama and MacBeth (1973) wherein separate cross-sectional versions of (2) are estimated for each of the survey years and then the estimated coefficients from each of the annual cross sections are averaged for all of the relevant explanatory variables. Further, we also include in the estimation process various additional terms to account for the interaction between regressors (e.g., $R E T_{T} \mathrm{x}$ $\left.P A Y O U T_{T}\right)$ and indicator variables to assess behavior in the post-economic crash environment (e.g., $R E T_{T} \times D_{T}$, where $D_{T}$ equals 1 if $\mathrm{T}=2009,2010$, or 2011 and 0 otherwise).

Table 7 lists the calculated coefficients for each of the hypothesized determinants for endowment spending rule changes, along with the associated t-statistics in parentheses, and the $R$-squared values for each regression. To begin with, Panel A reports findings for the three forms of the probit model using all of the available data (i.e., an unconditional specification of POLCHG where each endowment from every annual survey is included whether the spending policy was changed or not and without any additional restrictions). Panel B then presents a modified analysis by focusing on just those rule changes that subsequently resulted in a larger payout from the endowment portfolio. Panel C re-estimates the unrestricted model from Panel A for two non-overlapping subsets of the endowment fund sample determined by the relative amount an institution's budget that the payout represented over the 2009-2011 fiscal years. Specifically, Panel C reports separate sets of estimated coefficients from (2) for funds that fall in the highest and lowest PCTBDGT quartiles in the sample. ${ }^{31}$ Finally, Panel D reports regression estimates for two non-overlapping subsets of the endowment fund sample according to whether the sponsoring institution either did or did not invoke a special spending appropriation in Year T.

Looking first at the two fixed effects (FE) panel data regressions for the entire sample (Panel A), the most statistically meaningful determinants of spending rule changes are $L O G A U M$,

\footnotetext{
${ }^{31}$ As discussed earlier, data for the percentage of an institution's budget supplied by the annual payout from its endowment portfolio has only been available since the 2009 survey year. We make the implicit assumption with our analysis in Panel $\mathrm{C}$ that the PCTBDGT variable for a given fund is stable across time on a relative basis, meaning that the set of endowments with the greatest (least) budget responsibility does not change in a material way from one year to another.
} 
$P A Y O U T$, and RET. In particular, the strong positive relationship between fund size and POLCHG suggests that it is the largest endowments that are the most likely to alter their spending policies, a finding consistent with the notion that the greater degree of organizational flexibility that they possess permits a greater ability to make adjustments to all aspects of their operations. The t-statistics for the reported coefficients (i.e., 4.78 for the Year FE parameter of $0.08,4.24$ for the Year/Fund FE parameter of 0.07 ) indicate that this relationship is highly tractable even after controlling for the possibility of variables omitted from the analysis, both across time and between endowments. Beyond that, the Fama-MacBeth coefficient for $L O G A U M$ is also statistically reliable, which is especially notable given that this t-statistic (i.e., 5.79) is based on averaging parameter estimates from eight annual cross sections. ${ }^{32}$

The two other significant relationships documented in Panel A involve the level of the endowment's actual payout and the return to its investment portfolio. As predicted in Section 5.1, the coefficients for both the PAYOUT and RET variables are negative, implying that fund's that have produced smaller past payout levels and generated smaller investment returns are more likely to adjust the spending rules in the future. The coefficients for PAYOUT from the two FE models are particularly strong (e.g., a t-statistic of 5.51 for the Year FE parameter of -8.74), but the statistical significance of this variable is attenuated somewhat in the more severe conditions of the Fama-MacBeth model although the sign of the coefficient does not change. The same pattern holds for the relationship between POLCHG and RET as well, with the additional observation that the negative effect becomes even stronger starting with the 2009 fiscal year $\left(R E T_{2009-2011}\right)$, emphasizing the effect that the financial market crisis had on running a university endowment fund. It is also interesting to note that the interaction between return and payout variables $\left(R E T_{T} \times P A Y O U T_{T}\right)$ is also a significant determinant of $P O L C H G$, but in a way that mitigates the two separate effects just described. Specifically, funds with lower past returns and lower past payouts are less likely to change their spending rules more frequently, a finding that is difficult to explain beyond the possibility that these funds may also face more organizational barriers to affecting operating changes of any kind.

There are two other findings in involving these probit regressions for the entire unrestricted sample worth noting. First, endowment funds with a larger allocation to alternative assets tend to be less likely to modify their spending policies, as indicated by the consistently negative

\footnotetext{
${ }^{32}$ Since the specification in (2) is a probit equation, it is also useful to provide an economic interpretation for the estimated coefficients. For instance, the $L O G A U M$ parameter of 0.07 for the Year/Fund FE model corresponds to an increase in the probability of altering the spending policy of $0.15 \%$ for each incremental $\$ 10$ million in the size of the endowment's portfolio. For perspective, recall from the sample overview in Table 1 that the AUM for the average endowment in 2011 was $\$ 508.09$ million.
} 
parameter values on $A L T I N V$. Surprisingly, this relationship becomes more significant in the Fama-MacBeth regression than in either of the FE specifications. Since, as noted before, funds with larger alternative asset investments often produce higher risk-adjusted returns, this outcome suggests that there may be additional aspects of investment performance beyond nominal portfolios returns (i.e., RET) that are important in explaining the tendency to adjust formal spending mandates. Second, the effects that both the benchmark-level risk of the fund $(V O L)$ or its external contributions from donors (DONATE) had on POLCHG were negligible. The former is not necessarily unexpected given the finding of Brown, Garlappi, and Tiu (2010) that endowments tend to target similar policy volatilities. However, it is surprising that the impact that supplemental contributions to the fund has on the decision to adjust spending policy is extremely unreliable as well as of the wrong sign.

Panel B of of Table 7 re-examines these relationships after altering the POLCHG variable by assigning a value of 1 only to those observations for which (i) the spending rule was changed at Year $\mathrm{T}+1$, and (ii) $P A Y O U T_{T+1}$ exceeds $P A Y O U T_{T} \cdot{ }^{33}$ Presumably, this modification allows us to focus on those endowments whose express intention in changing their long-term spending mandate was to increase the future payout level of the fund. While the main findings from Panel A continue to hold (e.g., large endowments with smaller past payout levels and lower past returns are more likely to change their rules), these new findings indicate some interesting differences. Most notably, the relationship between PAYOUT and POLCHG becomes much more strongly negative than before, even becoming statistically significant in the Fama-MacBeth specification. This does indeed suggest that the experience of low past payout rates is a major factor driving an institution to seek a more accommodating set of rules. Further, there is also evidence that, for these specific funds, investing to a greater extent in alternative assets makes changing their policies more likely, which is consistent with the argument that increased illiquidity in the investment portfolio makes that dimension of the Board's decision-making less flexible. Interestingly, it is also the case that the portfolio's volatility level now matters, with the significant positive coefficient for $V O L$ predicted in Section 5.1 obtaining. Finally, the interaction term between $P A Y O U T$ and RET and the indicator variable highlighting returns in the post-crisis period are no longer statistically reliable.

The results contained in Panel $\mathrm{C}$ restore the original definition of POLCHG (i.e., assigns a value of 1 for any spending rule adjustment), but divides the endowment sample into two

\footnotetext{
${ }^{33} \mathrm{By}$ this construction, spending rule changes that did not result in an increased payout level are assigned a value of 0 , so that the total number of observations in the sample does not change, but the number of observations for which POLCHG takes the value of 1 is reduced. These frequencies are listed in the exhibit for each set of regression output.
} 
sub-groups representing the largest and smallest quartiles ranked by the average value of the PCTBDGT variable over the 2009-2001 period. The display lists a full set of probit regression findings for each of these sample divisions. ${ }^{34}$ The surprising result from a comparison of Panel C1 (High PCTBDGT) and Panel C2 (Low PCTBDGT) is that this variable appears to make virtually no difference to the fundamental relationships between POLCHG and its underlying determinants. For both sample divisions, the only variable that shows both the predicted sign and consistent statistical significance is PAYOUT, although LOGAUM does appear to be a stronger explanatory factor in the High PCTBDGT subsample. Portfolio returns in Year T are not statistically reliable for either budget quartile, whether viewed over the entire sample period or just in the post-crisis years.

One possible explanation for PCTBDGT's lack of influence is that, if an educational institution has the ability to extract incremental payouts from its endowment portfolio on a temporary basis, it may not need to change its permanent spending rules with any greater or lesser frequency regardless of how much of the budget the fund must cover. Thus, it could be the case that the presence of special appropriation measures mitigate the influence of budget percentage constraints. The final panel of Table 7 reports spending rule determinant regression output for those funds that either did not (Panel D1) or did (Panel D2) make use of a special payout appropriation during the last three years of the sample period for which this data was reported. The results support the notion that it is the set of endowments that do not-perhaps cannot - use temporary appropriations that changes its permanent spending rules in a more predictable manner, as indicated by the sign and statistical reliability of the PAYOUT and LOGAUM determinants. Neither these variables are statistically significant for the "Uses Appropriations" subsample in Panel D2, an outcome consistent with the spending rule transition results in Section 4.2 that showed endowments using special payouts were more likely to retain their permanent policies from one year to the next.

\section{The Interaction Between Spending Policy, Asset Allocation, and Investment Performance}

The findings reported so far support three stylized conclusions. First, the governing authorities of university endowment funds have changed both their spending policies and investment strategies (i.e., asset allocation weights) quite often over the past several years. Second, at least with

\footnotetext{
${ }^{34}$ To get a better sense of the range across the entire sample in the percentage of an institution's budget that the endowment fund is responsible for producing, the values of the three-year average PCTBDGT variable falling at the 75 th and 25 th percentiles are $13.2 \%$ and $1.0 \%$, respectively.
} 
respect to spending policy changes, these modifications appear to occur too frequently to be consistent with hypothesized behavior given the relatively invariant nature of the institution's long-term investment problem. Third, patterns in spending rule changes are significantly related to certain characteristics of the endowment's operations and the investment performance of the portfolio. In this section, we address two additional questions that involve the interaction between the endowment's spending policy decision and both its ex ante investment policy decision and the ex post policy-adjusted portfolio performance.

\subsection{The Relationship Between Changes in Spending Rules and Investment Policy}

As the introductory discussion in Section 1 suggests, a strong argument (e.g., Litvack, Malkiel, and Quandt (1974)) can be made that the most compelling way to organize an investment management operation begins with a clear definition of the institution's investment problem and then designs a portfolio strategy that represents the "optimal" solution. In the context of university endowments, such a sequence of events clearly implies that the development of the endowment's spending policy should both precede and inform the development of its investment policy. However, it is also plausible (e.g., Dybvig (1999)) that spending and investment policies are best determined simultaneously. From the preceding analysis on the frequency and determinants of spending policy adjustments, it is not altogether clear which (if either) of these predictions is true.

To establish more precisely the nature of the interaction between spending rule changes and asset allocation changes for our endowment fund sample, we begin by defining a measure that captures the essence of how Endowment E's investment strategy evolves from Year T-1 to Year T. Specifically, for each fund, we create an index of the change in the allocation weights (i.e., $A A C H G_{T}^{E}$ ) by summing the absolute values of the differences in the actual investment levels for each of the ten asset classes representing the investable universe for the NACUBO sample during consecutive years:

$$
A A C H G_{T}^{E}=\sum_{i=1}^{10}\left|w_{i, T}^{E}-w_{i, T-1}^{E}\right|
$$


Notice that, by construction, higher levels of $A A C H G$ indicate a greater adjustment in the endowment's asset class investment strategy, due to either a change in its policy-level strategic allocation weights or a tactical rotation permitted within the existing policy. ${ }^{35}$

To see whether spending rule changes are more likely to precede or follow asset allocation changes, we use a vector autoregression (VAR) process to estimate the structural relationship between the two variables. Specifically, we estimate the $\operatorname{VAR}(1)$ model using: (i) $P O L C H G_{T+1}$ and $A A C H G_{T}$; and (ii) $P O L C H G_{T}$ and $A A C H G_{T+1}$. Our null hypothesis is that the second form of the model (i.e., spending changes leading asset allocation changes) should provide the stronger results. The specific forms of the two panel data regression equations comprising the VAR system are:

$$
\begin{aligned}
\operatorname{POLCHG}(T+1)= & a_{1}+b_{11} \operatorname{POLCHG}(T)+b_{12} A A C H G(T) \\
& +c_{11} \operatorname{LOGAUM}(T)+c_{12} P A Y O U T(T)+e_{1, T+1},
\end{aligned}
$$

and:

$$
\begin{aligned}
A A C H G(T+1)= & a_{2}+b_{21} \operatorname{POLCHG}(T)+b_{22} A A C H G(T) \\
& +c_{21} \operatorname{LOGAUM}(T)+c_{22} \operatorname{PAYOUT}(T)+e_{2, T+1} .
\end{aligned}
$$

Given their significance in earlier findings, we include LOGAUM and PAYOUT as control variables in the estimation of (4) and (5).

Table 8 tabulates these results, which contain two substantive findings. First, from (4), it is apparent that $P O L C H G_{T+1}$ is significantly and positively related to $P O L C H G_{T}$ (i.e., estimated coefficient of 0.2550 with a t-statistic of 23.93) but its relationship with $A A C H G_{T}$ is not statistically reliable (i.e., t-statistic of -0.65). This supports the conclusion that spending rule changes are indeed persistent over time, at least for the half of the endowment sample that altered their policies at all. Further, it also highlights the fact that institutions are not adjusting their spending rules in response to previous changes in asset allocation strategies that may have produced less-than-desirable portfolio performance. This is consistent with a hypothesized view of the investment management process holding that the statement of the investment problem should not be determined by the myriad aspects of the investment decision-making process.

The second main finding in Table 8 involves the estimated coefficients for (5), which indicate that the relationship between $A A C H G_{T+1}$ and $A A C H G_{T}$ is also statistically significant (i.e.,

\footnotetext{
${ }^{35}$ The measure in (3) is a straightforward variation of the class of statistical distance measures used elsewhere in the financial economic literature; see, for instance, Hansen and Jagannathan (1997).
} 
estimated coefficient of 0.2815 with a t-statistic of 13.72 ). This means that the typical endowment adjusts its asset allocation weights in a persistent manner over time, which can in turn be interpreted as suggesting that this dimension of its investment policy is not static. Further, $A A C H G_{T+1}$ is positively correlated with $P O L C H G_{T}$, although at a marginal level of statistical significance (i.e., estimated coefficient of 0.0165 with a t-statistic of 1.54 ). The implication of this finding is that future asset allocation changes are tied to past adjustments in spending rules, albeit with an attenuated level of strength. Specifically, an endowment that altered its payout rule in one year is more likely to modify its asset class-level investment strategy in the next year. This outcome implies that whatever it was that caused the fund to change its payout policy in the first place does indeed lead to a subsequent allocation adjustment in its portfolio construction.

\subsection{Spending Rule Changes and Endowment Investment Performance}

The findings in Table 7 provide compelling evidence that the nominal level of an endowment fund's investment performance helps influence the institution's future spending policy decisions. It is not clear, though, whether endowments that change their spending rules perform appreciably better or worse than those that maintain stable payout mandates. A complication in addressing this issue is that a simple comparison of total portfolio returns between the two groups is not sufficient since we know that there is considerable variation in the asset allocation patterns - particularly for the alternative asset classes - across the sample and that these allocation differences are alone sufficient to produce substantial variation in measured returns. Therefore, we proxy Endowment E's active return in Year T $\left(A L P H A_{T}^{E}\right)$ as the difference between its actual total return $\left(R_{T}^{E}\right)$ and its associated policy benchmark return $\left(R_{T}^{B}\right)$ :

$$
A L P H A_{T}^{E}=R_{T}^{E}-R_{T}^{B}=R_{T}^{E}-\sum_{i=1}^{10} w_{i, T}^{E} R_{i, T}^{B},
$$

where $w_{i}^{E}$ is the fund's allocation weight for the i-th asset class and and $R_{i}^{B}$ is the nominal return to the benchmark index representing the the i-th asset class. ${ }^{36}$ As in Brown and Tiu (2010), in the computation of (6) we use the following benchmark index definitions for each asset

\footnotetext{
${ }^{36}$ Strictly speaking, the calculation in (6) measures the portion of the endowment's active return that is associated with the endowment portfolio manager's security selection skills. For $A L P H A$ to include the contribution of both sources of active management skills (i.e., security selection and market timing), this calculation would need to be amended to include the set of strategic allocation weights from the endowment's investment policy statement (i.e., $\left.\left[w_{i}^{B}\right]\right)$. Unfortunately, the NACUBO/Commonfund database does not report these $\left[w_{i}^{B}\right]$ for many funds in any given annual survey or for any fund over the entire sample period. However, as Brown, Garlappi, and Tiu (2010) show, the portion of the endowment's true ALPHA generated by the manager's market timing skills is, on average, fairly negligible.
} 
class: U.S. Public Equity (CRSP Value Weighted), Non-U.S. Public Equity (MSCI World-Ex U.S.), Fixed-Income (Barclays Global Aggregate), Real Estate (NCREIF), Hedge Funds (HFRI Composite), Venture Capital (Cambridge Associates VC), Private Equity (Cambridge Associates PE), Natural Resources (GSCI), Cash (30-day U.S. T-bill), and Other Assets (not applicable).

We divide the overall endowment sample into two sub-groups according to whether a fund did not or did alter its spending rules at least once during the 2003-2011 period. (Recall from Figure 4 that each of these groups represent half of the overall sample.) Labeling these subsamples as the "No Change" and "Change" groups, respectively, we form both equal-weighted and market value-weighted portfolios of the endowments contained in each for the purpose of assessing investment performance. For the portfolios in each sub-group, we calculate the (i) average actual total return, (ii) the average policy benchmark return associated with each fund, and (iii) the average $A L P H A$ statistic, as measured in (6). The focus of the analysis is then to see whether the difference in average benchmark-adjusted returns for the No Change and Change portfolios (i.e., $\left[\operatorname{Avg} A L P H A^{N C}-A v g A L P H A^{C}\right]$ is equal to zero).

Table 9 lists the average $A L P H A$ and policy benchmark (i.e., $R^{B}$ ) returns to the equalweighted and value-weighted portfolios for both endowment sub-samples, along with the difference in the AvgALPHA calculations for each portfolio formation category. There are two primary conclusions to be drawn from these data. First, regardless of the institution's spending policy revision strategy, it appears that endowment fund managers are good investors. The reported average benchmark-adjusted returns are uniformly positive and, at about 100 basis points per annum, relatively large (e.g., $0.90 \%$ for the equal-weighted No Change portfolio, $1.22 \%$ for the value-weighted Change portfolio). While the high level of cross-sectional performance volatility within the sub-samples renders these performance measures statistically insignificant (e.g., t-statistics of 0.59 and 0.81 for the two portfolios mentioned above), it nevertheless is the case that the average fund manager in each sub-group produced returns at least as good as his or her policy benchmark.

The second notable finding from the exhibit is that there is virtually no difference in the risk-adjusted investment performance statistics between those endowments that changed their spending policies with some frequency or those that maintained a single set of rules throughout the sample period. The reported values for $\left[A v g A L P H A^{N C}-A v g A L P H A^{C}\right]$ - which is shown as "Diff" in the next-to-last row - are just $-0.04 \%$ (EW) and $0.14 \%(\mathrm{VW})$, with respective tstatistics of -0.32 and 0.27 . Interestingly, there is a marginally significant difference in policy benchmark returns between the two categories (i.e., $-0.12 \%(\mathrm{EW})$ and $-0.39 \%(\mathrm{VW})$, which 
suggests that they may face slightly different initial risk budgets. However, once any such risk differentials are accounted for (even implicitly in the benchmark adjustment process), there is no indication that the frequency with which an institution revises its spending policy has any impact - either adverse or positive - on the returns its endowment portfolio produces.

\section{Concluding Comments}

The sponsors and asset managers associated with an endowment fund face an interesting intergenerational investment problem with at least two conflicting goals: they need to produce steady increases in the portfolio's market value to insure the security and long-term viability of the institution and future beneficiaries, but they also need to produce sufficient current income to sustain existing operations. The endowment's spending policy statement is the document in which the governing authority of the institution expresses its intentions as to how this tension should be resolved. Once the permanent spending policy is set, prudent decisions can then be made concerning the investment policies and strategies that should be followed. While there is growing body of research focusing on endowment investment practices (e.g., Acharya and Dimson (2007), Brown, Garlappi, and Tiu (2010), Dimmock (2012)), there is a general dearth of analysis concerning the salient aspects of the spending policy decision, which is curious given its central role in the endowment management process.

In this study, we have addressed this perceived need by providing a comprehensive examination of the spending policy decisions made by over 800 university endowment funds during the period from 2003 to 2011. For each fund during every year, we categorized the specific spending rule and policy payout rate it used and documented how frequently and why the sponsoring institution was motivated to change those mandates over time. While there is a considerable degree of variation within the sample, we showed that a sizeable majority of endowments adopt a payout formula based on a percentage of a moving average of the portfolio's past values. However, the most surprising result in our analysis is that endowments altered their permanent spending policies far more often than what theory would predict given the nature of the investment problem they face; on average, $25 \%$ of the funds adjusted their policies in any given year and half of the funds surveyed amended their stated rules at least once during the sample period. We also demonstrated that large endowments that had produced lower past returns and had lower actual payout levels were more likely to alter their long-term spending policies, but that funds with the ability to use special appropriations on a temporary basis were less likely to adjust their permanent rules, a tendency that became more pronounced in the aftermath of 
the global economic crisis of 2008. Further, we showed that payout rule changes are more likely to precede adjustments to the fund's asset allocation strategy than the other way around and that the tendency for institutions to alter both types of policy is strongly persistent over time. Finally, despite their disparate characteristic profiles, we found no difference in the benchmarkadjusted investment performance for portfolios of endowments that either did or did not alter their spending policies during the sample period.

The intriguing questions that remain to be addressed are whether changing the permanent spending policy too frequently represents sub-optimal behavior on the part of the endowment's decision makers and, if so, what the economic cost of such actions might be? Those may well be questions that are not easily answered, particularly in the absence of specific information about the investment problem an institution faces and whether sufficient changes in its underlying circumstances took place to warrant a revision of its previous rules. From our analysis, we do know that any expenses associated frequent payout policy revisions is not borne at the portfolio investment level. However, a diminution in risk-adjusted return performance is not the only possible cost that a fund might bear as a result of these changes - use of Board and Staff time, misaligned objectives for the institution, loss of confidence among sponsors and donors, for example - and, while challenging, quantifying these values might tell a very different story. An equally challenging effort would involve trying to define and measure the incremental benefits that accrue to institutions that make frequent changes to their permanent policy; if such revisions to the formal statement of its investment problem do not lead to asset allocation solutions that generate superior returns, what might the benefits of those changes be? Certainly, considering these issues is fruitful ground for future research. 


\section{Appendix: A Taxonomy of Spending Policy Rules}

The statistical summary presented in Table 3 classifies the spending rules used by our sample of college and university endowment funds into seven separate categories. Further, several of the seven broad categories can be meaningfully split into two or more sub-divisions. These classifications are based on those used in practice as defined and collected by the National Association of College and University Business Officers (NACUBO) and the Commonfund; see Mehrling, Goldstein, and Sedlacek (2005), Sedlacek and Jarvis (2010) and Murray (2011) for more details.

Listed below are spending rule categories and sub-categories used in this study, along with descriptions and, where applicable, the formulas used for determining endowment payouts.

1. Decide on an Appropriate Rate Annually: Gives the governing authority complete discretion to determine the spending rate it deems appropriate on a yearly basis.

2. Increase Prior Year's Spending by a Percentage: Adjusts spending upwards each year, using either a simple formula or one based on the inflation rate.

(i) Increase Prior Year's Spending by a Pre-Specified Percentage: Determines the annual payout as the previous year's payout adjusted upwards by a pre-specified rate.

(ii) Increase Prior Year's Spending by the Inflation Rate: Determines the annual payout as the previous year's payout adjusted for a pre-specified inflation rate $(\mathrm{I})$; i.e., $(\text { Payout })_{t}=$ $(\text { Payout })_{t-1} \mathrm{x}(1+\mathrm{I})$.

(iii) Increase Prior Year's Spending by a Collared Inflation Rate: Determines the annual payout as the previous year's payout adjusted for the actual inflation rate (e.g., CPI, HEPI) during the investment period, subject to pre-specified minimum and maximum rate levels.

3. Spend a Percentage of a Moving Average of Market Values: Determines annual payout as a percentage ( $\mathrm{P} \%$, which can be either fixed or variable) of an average of beginning-ofperiod market values over a pre-specified series of past periods; i.e., $\mathrm{P} \% \mathrm{x}$ Average $\left(A U M_{0}\right.$, $\left.A U M_{-1}, \ldots, A U M_{-N}\right)$, where $A U M_{-t}$ represents the fund's assets under management $\mathrm{t}$ periods in the past.

(i) Spend a Pre-Specified Percentage of Moving 12-Quarter Average of Market Values: Uses a quarterly frequency over three years to calculate the moving average of fund AUM. 
(ii) Spend a Pre-Specified Percentage of Moving 3-Year Average of Market Values: Uses an annual frequency over three years to calculate the moving average of fund AUM.

(iii) Spend a Pre-Specified Percentage of Moving 20-Quarter Average of Market Values: Uses a quarterly frequency over five years to calculate the moving average of fund AUM.

(ii) Spend a Pre-Specified Percentage of Moving 5-Year Average of Market Values: Uses an annual frequency over five years to calculate the moving average of fund AUM.

(v) Spend a Percentage of Moving Average of Market Values, Other Than 12 Quarters/3 Years or 20 Quarters/5 Years: Uses a percentage-of-moving-average approach based on a different frequency (e.g., semi-annual), number of periods (e.g., seven years), or percentage determination method (e.g., variable inflation rate) than those listed above.

4. Spend a Percentage of Current Yield: Spend a percentage (Y\%, which can be either fixed or variable) of current income generated during the investment period; i.e., Y\% x Income.

(i) Spend a Pre-Specified Percentage of Current Yield: Spend a pre-determined percentage (less than 100 percent) of current income generated during the investment period.

(ii) Spend All Current Yield: Spend all current income generated during the investment period $(\mathrm{Y} \%=100 \%)$.

(iii) Spend All Dividends or Earnings: Spend all income generated during the investment period specifically through dividend payments or earnings.

(iv) Spend a Percentage of Current Yield Determined Annually: Spend a pre-determined percentage (possibly 100 percent) of current income generated during the investment period, where the percentage spent is determining on a yearly basis.

5. Spend a Percentage of Assets Under Management (AUM): Determines annual payout as a percentage $\mathrm{P} \%$ of the beginning-of-period fund $\mathrm{AUM}$ for the current period; i.e., $\mathrm{P} \% \mathrm{x} A U M_{0}$. (i) Spend a Pre-Specified Percentage of Beginning-of-Period AUM: Specify a pre-determine level for $\mathrm{P} \%$.

(ii) Does Not Spend At All: The endowment does not make distributions in current year; this can be interpreted as setting a pre-specified percentage spending rate of zero.

6. Hybrid Rules: Uses a simple formula to combine two or more payout categories into a single spending rule.

(i) Yale Rule: A weighted average calculated as X percent of prior year's spending, adjusted 
for inflation, and (1-X) percent of a pre-specified payout rate multiplied by beginning-of-period endowment AUM (i.e., combination of Categories 2 and 5). The value for $\mathrm{X}$ was fixed at 80 percent throughout the sample period.

(ii) Stanford Rule: A variation of the Harvard Rule based on a different smoothing proportion using $\mathrm{X}=60$ percent.

(iii) Other Combinations: Combines two or more payout categories other than those listed above.

\section{Other Payout Rules:}

(i) Rules Not Otherwise Classified: Uses a formula or approach that differs from those listed above (e.g., increases spending by a pre-specified fixed percentage unless a political or economic contingency event occurs, in which case the governing authority uses its discretion in setting the payout amount.)

(ii) Insufficient Information: Endowment did not provide a complete set of information that allowed for the classification of its spending policy. 


\section{References}

Acharya, Shanta, and Elroy Dimson, 2007, Endowment Asset Management (New York: Oxford University Press).

Black, Fischer, 1976, The investment policy spectrum: Individuals, endowment funds, and pension funds, Financial Analysts Journal 32, 23-31.

Blume, Marshall E., 2010, Endowment spending in volatile markets: What should fiduciaries do?, Review of Quantiative Finance and Accounting 35, 163-178.

Bodily, Samuel L., and Chelsea C. White, 1982, Optimal consumption and portfolio strategies in a discrete-time model with summary-dependent preferences, Journal of Financial and Quantitative Analysis 17, 1-14.

Brinson, Gary P., L. Randolph Hood, and Gilbert L. Beebower, 1986, Determinants of portfolio performance, Financial Analysts Journal 42, 39-48.

Brown, Jeffrey R., Stephen G. Dimmock, Jun-Koo Kang, and Scott Weisbenner, 2010, How university endowments respond to financial market shocks: Evidence and implications, Working Paper, National Bureau of Economic Research.

Brown, Jeffrey R., Stephen G. Dimmock, and Scott Weisbenner, 2012, The supply and demand for charitable donations to higher education, Working Paper, National Bureau of Economic Research.

Brown, Keith C., Lorenzo Garlappi, and Cristian Tiu, 2010, Asset allocation and portfolio performance: Evidence from university endowment funds, Journal of Financial Markets $13,268-294$.

Brown, Keith C., and Cristian Tiu, 2010, Do endowment funds select the optimal mix of active and passive risks?, Journal of Financial Markets 8, 62-86.

Brown, Stephen J., William Goetzmann, Roger G. Ibbotson, and Steven A. Ross, 1992, Survivorship bias in performance studies, Review of Financial Studies 5, 553-580.

Cain, J. Harvey, 1960, Recent trends in endowment, Review of Economics and Statistics 42, 242-244.

Cejnek, Georg, Richard Franz, Otto Randl, and Neal Stoughton, 2012, A survey of university endowment management research, Research Institute for Capital Markets, Vienna Austria.

Dimmock, Stephen G., 2012, Portfolio choice, background risk, and university endowment funds, Review of Economics and Statistics forthcoming.

Dybvig, Philip H., 1999, Using asset allocation to protect spending, Financial Analysts Journal $55,49-62$.

Fama, Eugene F., and James D. MacBeth, 1973, Risk, return, and equilibrium: Empirical tests, Journal of Political Economy 81, 606-636.

Garland, James P., 2005, Long-duration trusts and endowments, Journal of Portfolio Management $31,44-54$.

Gilbert, Thomas, and Christopher Hrdlicka, 2012, Fairness and risk-sharing across generations: An application to university and non-profit endowments, Working Paper, University of Washington. 
Goetzmann, William N., and Sharon Oster, 2012, Competition among university endowments, Working Paper, National Bureau of Economic Research.

Hansen, Lars Peter, and Ravi Jagannathan, 1997, Assessing specification errors in stochastic discount factor models, Journal of Finance 52, 557-590.

Hansmann, Henry, 1990, Why do universities have endowments?, Journal of Legal Studies 19, $3-42$.

Hill, Joanne M., 2006, Alpha as a net zero-sum game, Journal of Portfolio Management 32, $24-32$.

Hoxby, Caroline M., 2012, Financial rules for universities based on their objectives and constraints, Working Paper, National Bureau of Economic Research.

Ibbotson, Roger G., and Paul D. Kaplan, 2000, Does asset allocation policy explain 40, 90, or 100 percent of performance?, Financial Analysts Journal 56, 26-33.

Kochard, Lawrence E., and Cathleen M. Rittereiser, 2008, Foundation 6 Endowment Investing (Hoboken, NJ: John Wiley \& Sons).

Lapovsky, Lucie, 2009, Endowment spending: External perceptions and internal practices, Commonfund Institute, Wilton CT.

Leibowitz, Martin L., 2005, Alpha hunters and beta grazers, Financial Analysts Journal 61, $32-39$.

- Anthony Bova, and P. Brett Hammond, 2010, The Endowment Model of Investing: Return, Risk, and Diversification (Hoboken, NJ: John Wiley \& Sons).

Lerner, Josh, Antoinette Schoar, and Jialan Wang, 2008, Secrets of the academy: The drivers of university endowment success, Journal of Economic Perspectives 22, 207-222.

Lerner, Josh, A. Schoar, and W. Wongsunwai, 2007, Smart institutions, foolish choices: The limited partner performance puzzle, Journal of Finance 42, 731-764.

Litvack, James M., Burton G. Malkiel, and Richard E. Quandt, 1974, A plan for the definition of endowment income, American Economic Review 64, 433-437.

Mehrling, Perry, Paul Goldstein, and Verne Sedlacek, 2005, Endowment spending: Goals, rates, and rules, in Forum for the Future of Higher Education (Washington D.C.: Educause).

Merton, Robert C., 1971, Optimum consumption and portfolio rules in a continuous-time model, Journal of Economic Theory 3, 373-413.

— , 1993, Optimal investment strategies for university endowment funds, in Charles T. Clotfelter, and Michael Rothschild, ed.: Studies of Supply and Demand in Higher Education (Chicago, IL: University of Chicago Press).

— , 2003, Thoughts on the future: Theory and practice in investment management, Financial Analysts Journal 59, 17-23.

Murray, Steve, 2011, Non-profit spending rules, Working Paper, Russell Investments.

Nettleton, Minot B., 1987, The impact of spending rules on endowments, in Cathryn E. Kittell, ed.: The Challenges of Investing for Endowment Funds (Institute of Chartered Financial Analysts and Dow Jones-Irwin). 
Samuelson, Paul A., 1969, Lifetime portfolio selection by dynamic stochastic programming, Review of Economics and Statistics 51, 239-246.

Sedlacek, Verne O., and William F. Jarvis, 2010, Endowment spending: Building a stronger policy framework, Commonfund Institute Wilton CT.

Swensen, David F., 2009, Pioneering Portfolio Management: An Unconventional Approach to Institutional Investment (New York: Free Press) 2nd edn.

Thaler, Richard H., and J. Peter Williamson, 1994, College and university endowment funds, Journal of Portfolio Management 21, 27-37.

Tobin, James, 1974, What is permanent endowment income?, American Economic Review 64, $427-432$.

Walda, John D., and John S. Griswold, 2011, Nacubo-commonfund study of endowments, National Association of College and University Business Officers Washington DC.

Woglom, Geoffrey, 2003, Endowment spending rates, intergenerational equity and the sources of capital gains, Economics of Education Review 22, 591-601. 


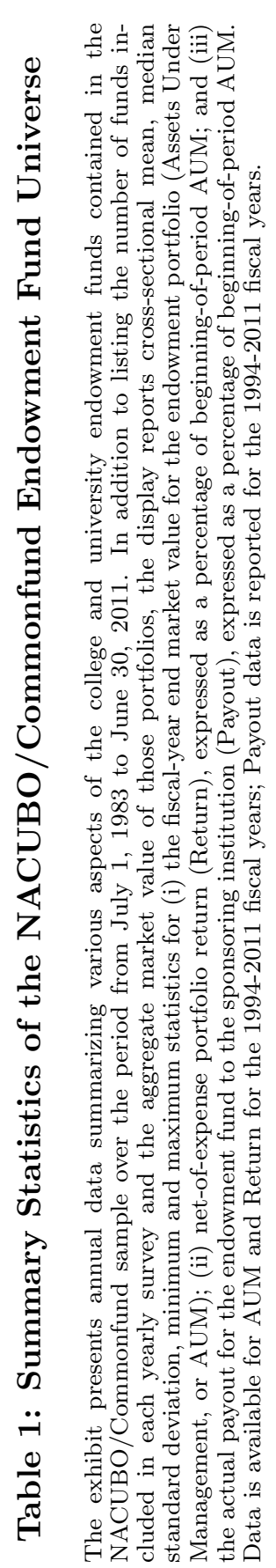

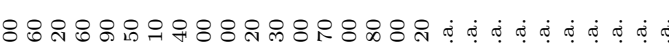

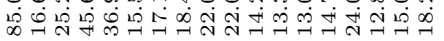

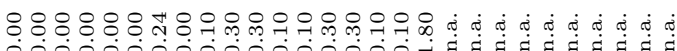

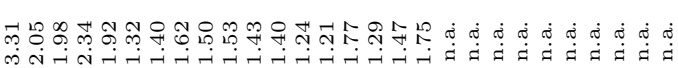

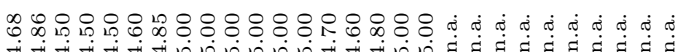

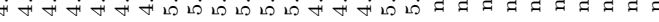

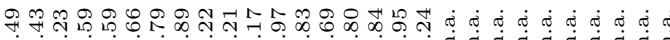

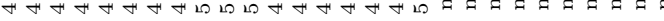

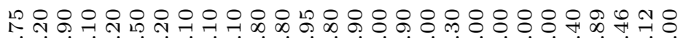

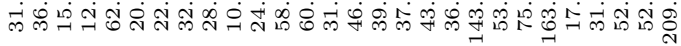

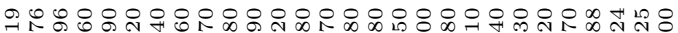
में

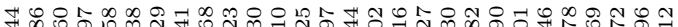

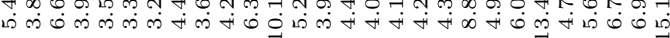

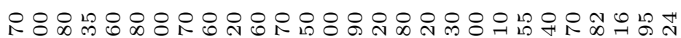

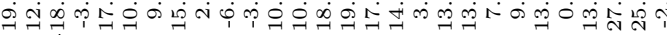

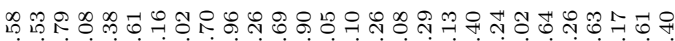

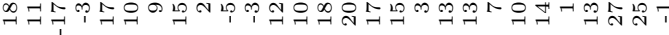

の

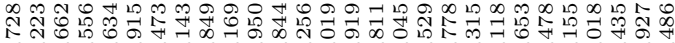

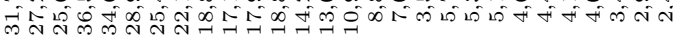

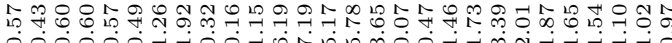

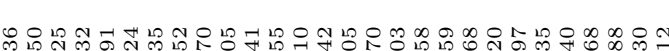

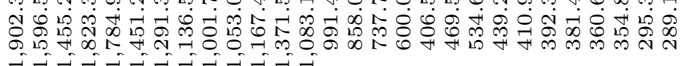

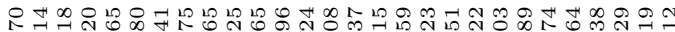

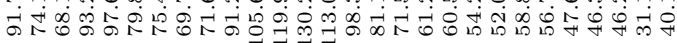

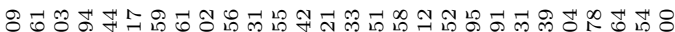
品

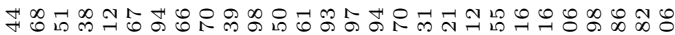

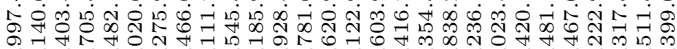

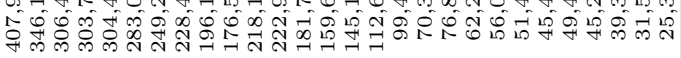

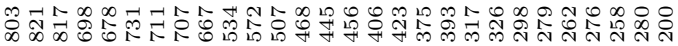

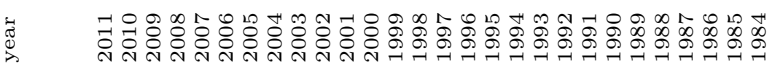




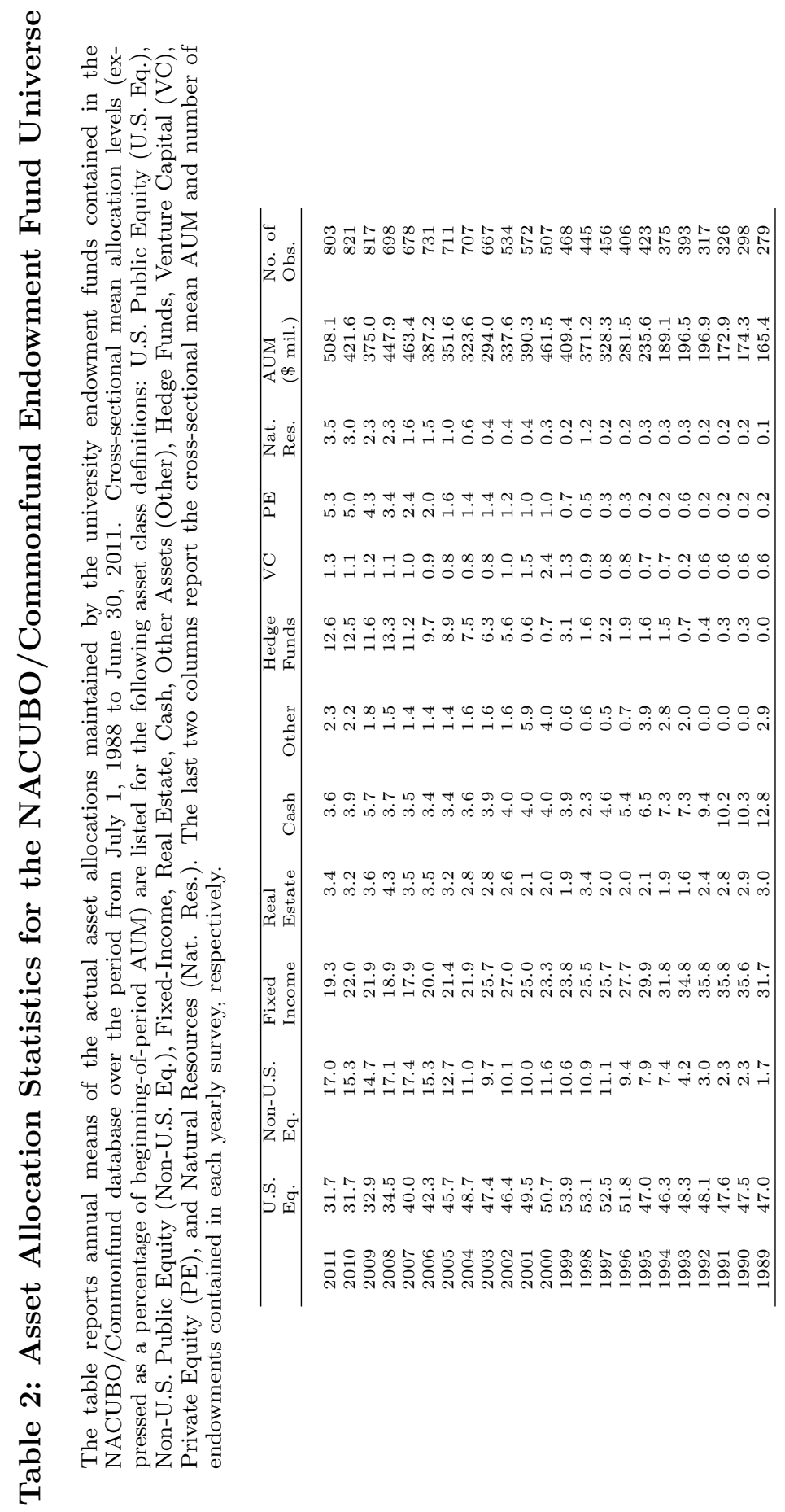




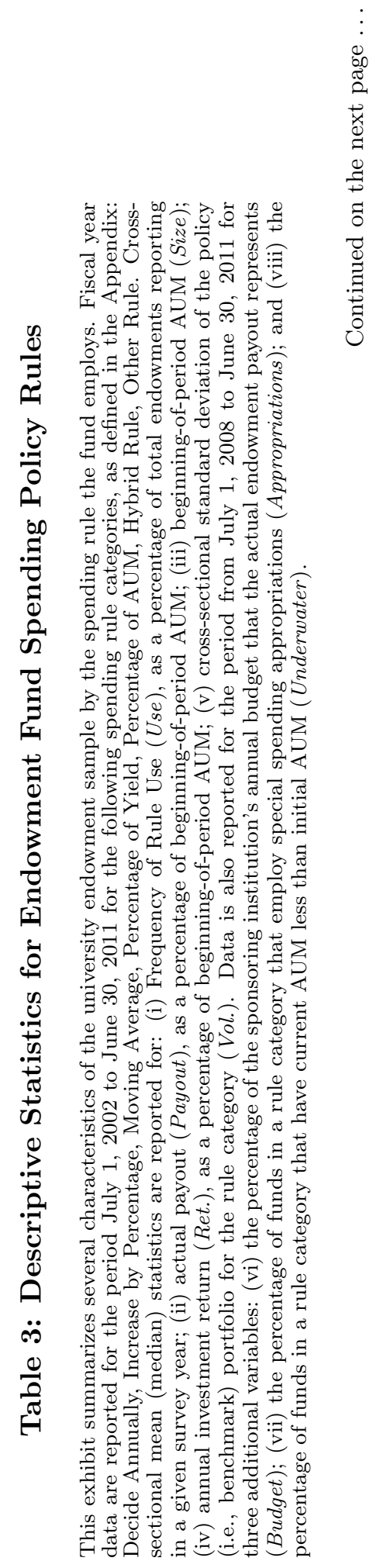




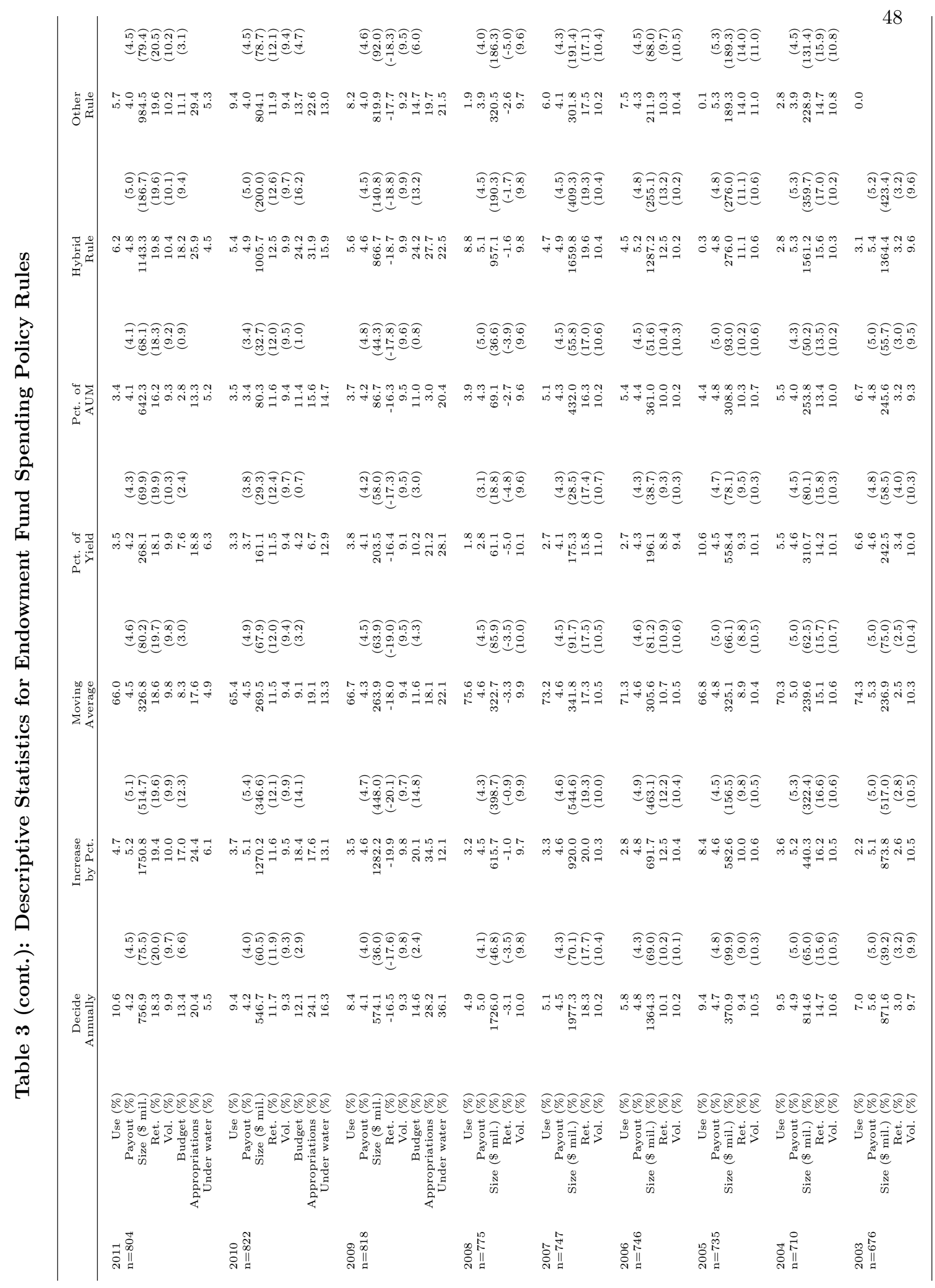




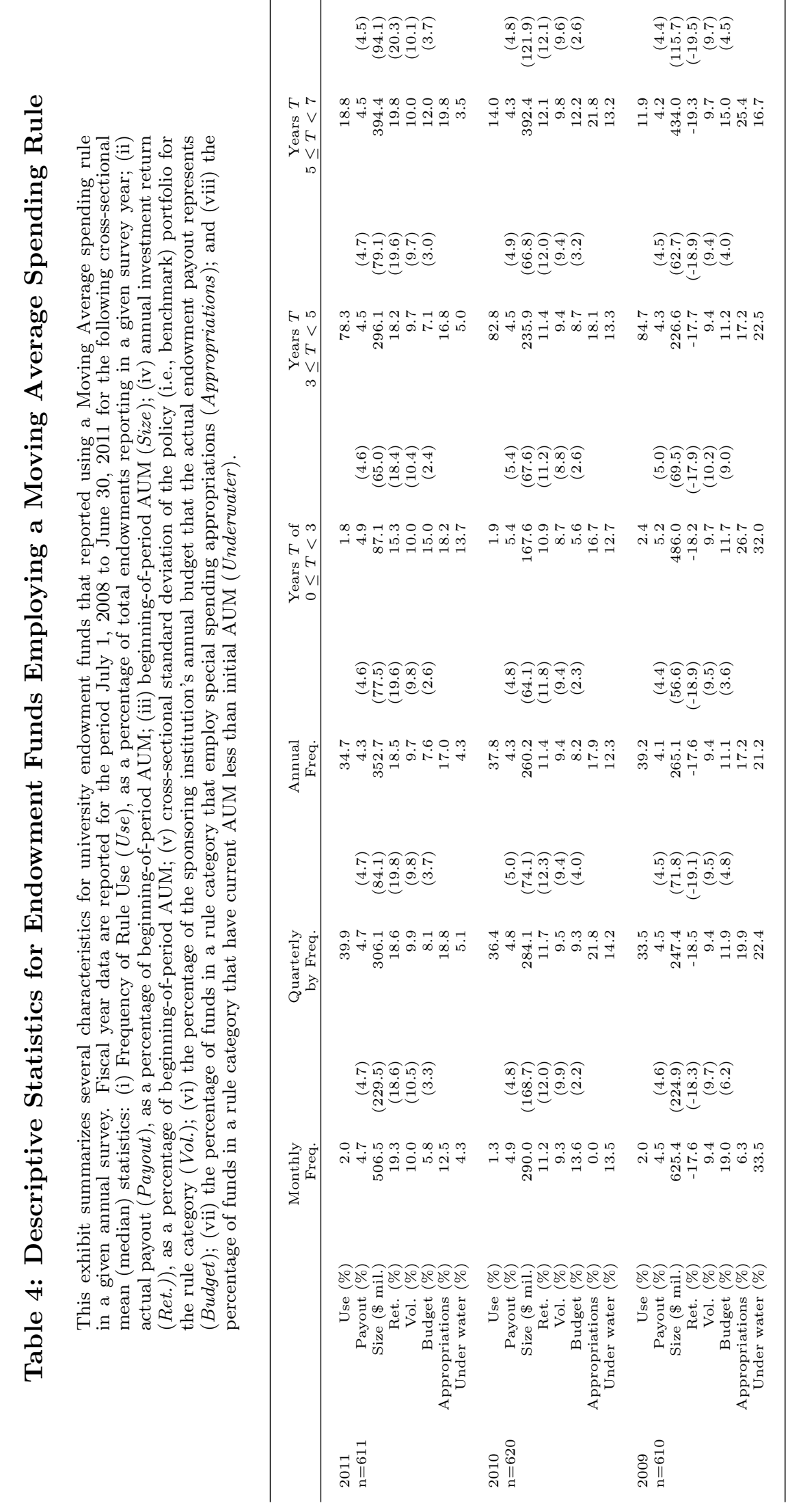

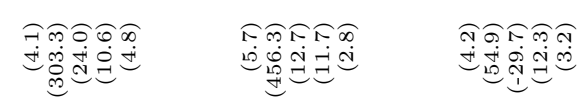

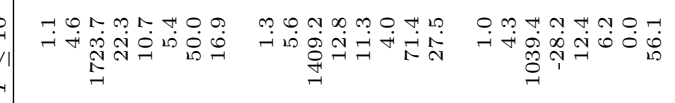




\section{Table 5: Changes in Endowment Spending Policy and Spending Rule Adoption}

This exhibit reports statistics summarizing how university endowment funds altered their spending policies (i.e., spending rule or stated policy payout rate, in Panel A) or just their spending rules (in Panel B) over the period July 1, 2002 to June 30, 2011 . Listed for each fiscal year $\mathrm{T}$ are: (i) the number of reporting funds in Year $\mathrm{T}$; (ii) the number of those funds also reporting in Year $\mathrm{T}+1$; (ii) the number of Year $\mathrm{T}+1$ reporting funds that maintained their Year $\mathrm{T}$ spending mandate; (iv) the number of Year $\mathrm{T}+1$ reporting funds that changed their Year $\mathrm{T}$ spending mandate; (v) the number of Year $\mathrm{T}$ funds not reporting in Year $\mathrm{T}+1$; and (vi) the ratio of funds that changed their Year $\mathrm{T}$ spending mandate in Year $\mathrm{T}+1$ and the total number of Year $\mathrm{T}$ funds.

Obs. Reported Maintained Changed Not Reported Pct.

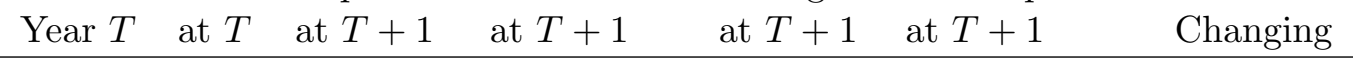

Panel A: Policy changes

$\begin{array}{llllrrr}2010 & \mathbf{8 5 0} & 782 & 519 & \mathbf{2 6 3} & 68 & 30.94 \\ 2009 & \mathbf{8 4 2} & 749 & 463 & \mathbf{2 8 6} & 93 & 33.97 \\ 2008 & \mathbf{8 6 4} & 675 & 514 & \mathbf{1 6 1} & 189 & 18.63 \\ 2007 & \mathbf{8 3 3} & 698 & 545 & \mathbf{1 5 3} & 135 & 18.37 \\ 2006 & \mathbf{8 1 6} & 683 & 610 & \mathbf{7 3} & 133 & 8.95 \\ 2005 & \mathbf{8 1 8} & 680 & 382 & \mathbf{2 9 8} & 138 & 36.43 \\ 2004 & \mathbf{7 5 5} & 661 & 392 & \mathbf{2 6 9} & 94 & 35.63 \\ 2003 & \mathbf{7 4 4} & 607 & 504 & \mathbf{1 0 3} & 137 & 13.84\end{array}$

Panel B: Rule changes

\begin{tabular}{llllrrr}
2010 & $\mathbf{8 5 0}$ & 782 & 663 & $\mathbf{1 1 9}$ & 68 & 14.00 \\
2009 & $\mathbf{8 4 2}$ & 749 & 618 & $\mathbf{1 3 1}$ & 93 & 15.56 \\
2008 & $\mathbf{8 6 4}$ & 675 & 514 & $\mathbf{1 6 1}$ & 189 & 18.63 \\
2007 & $\mathbf{8 3 3}$ & 698 & 613 & $\mathbf{8 5}$ & 135 & 10.20 \\
2006 & $\mathbf{8 1 6}$ & 683 & 652 & $\mathbf{3 1}$ & 133 & 3.80 \\
2005 & $\mathbf{8 1 8}$ & 680 & 382 & $\mathbf{2 9 8}$ & 138 & 36.43 \\
2004 & $\mathbf{7 5 5}$ & 661 & 392 & $\mathbf{2 6 9}$ & 94 & 35.63 \\
2003 & $\mathbf{7 4 4}$ & 607 & 504 & $\mathbf{1 0 3}$ & 137 & 13.84 \\
\hline
\end{tabular}




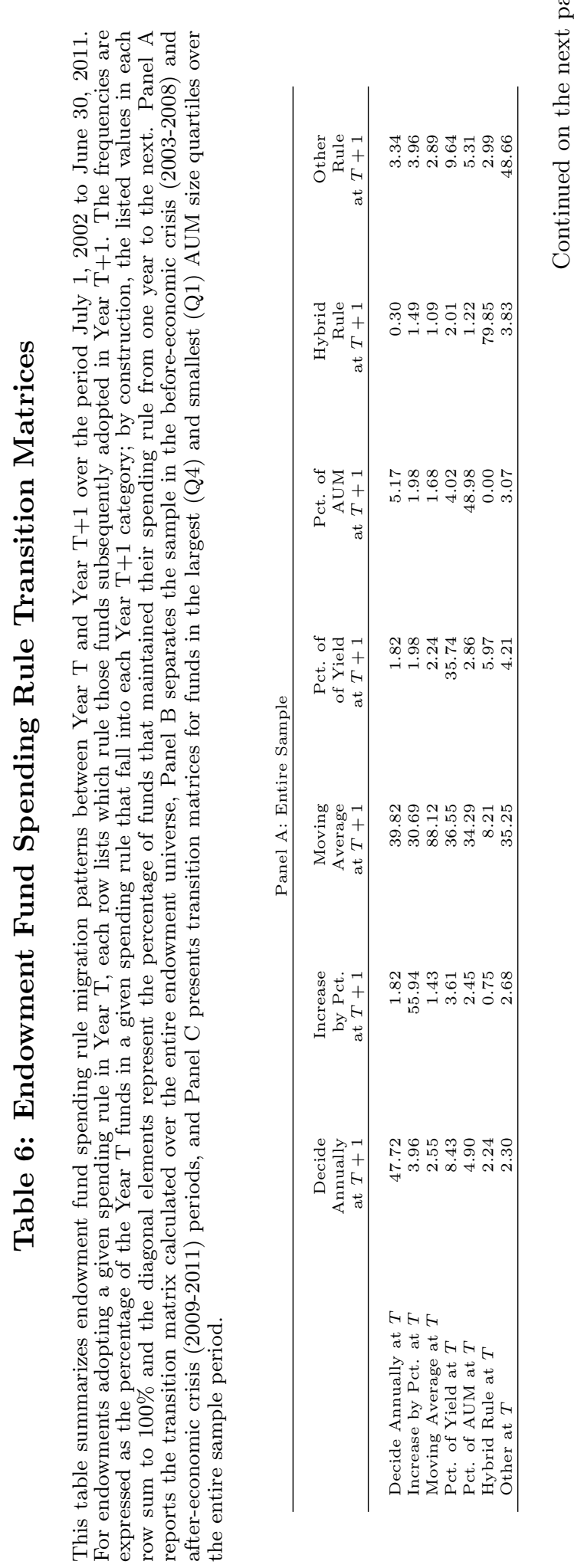




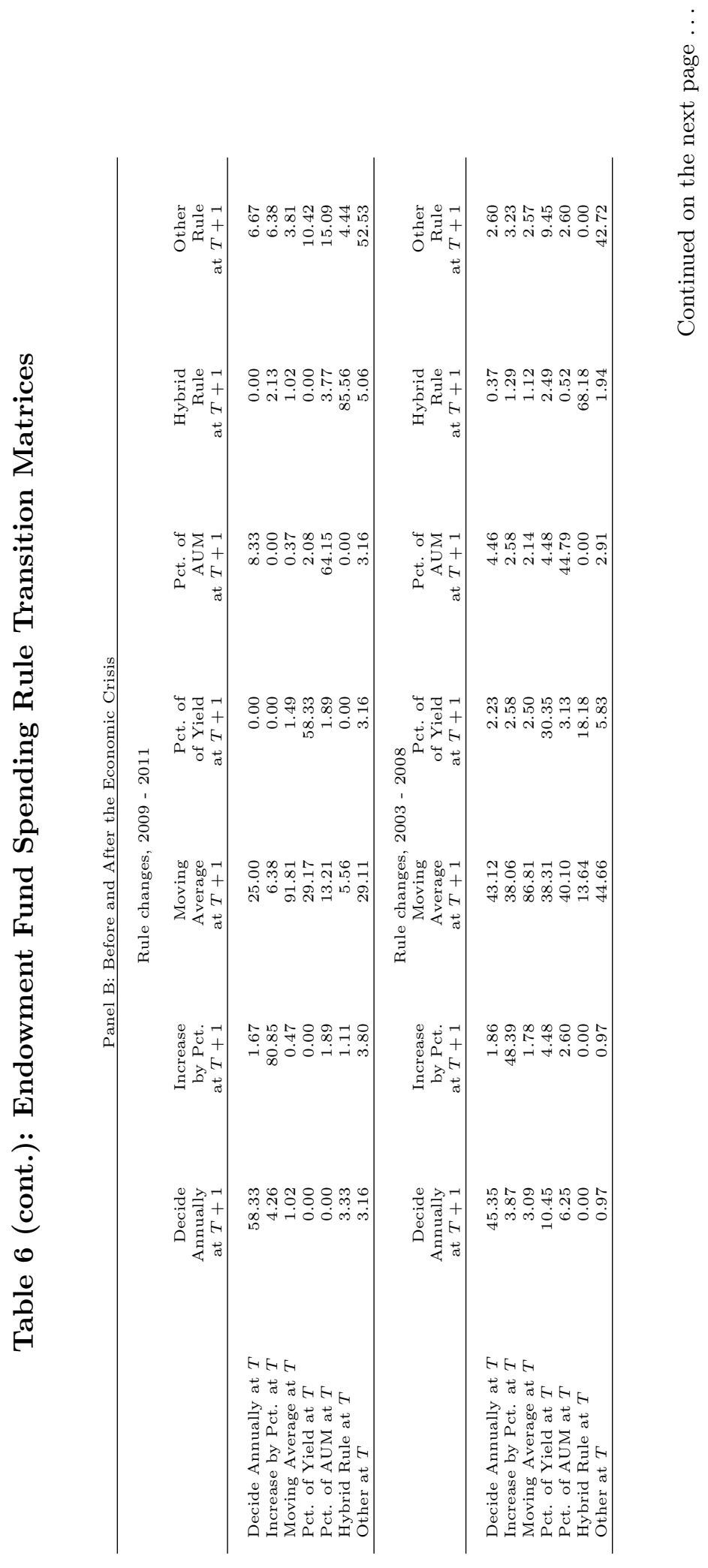




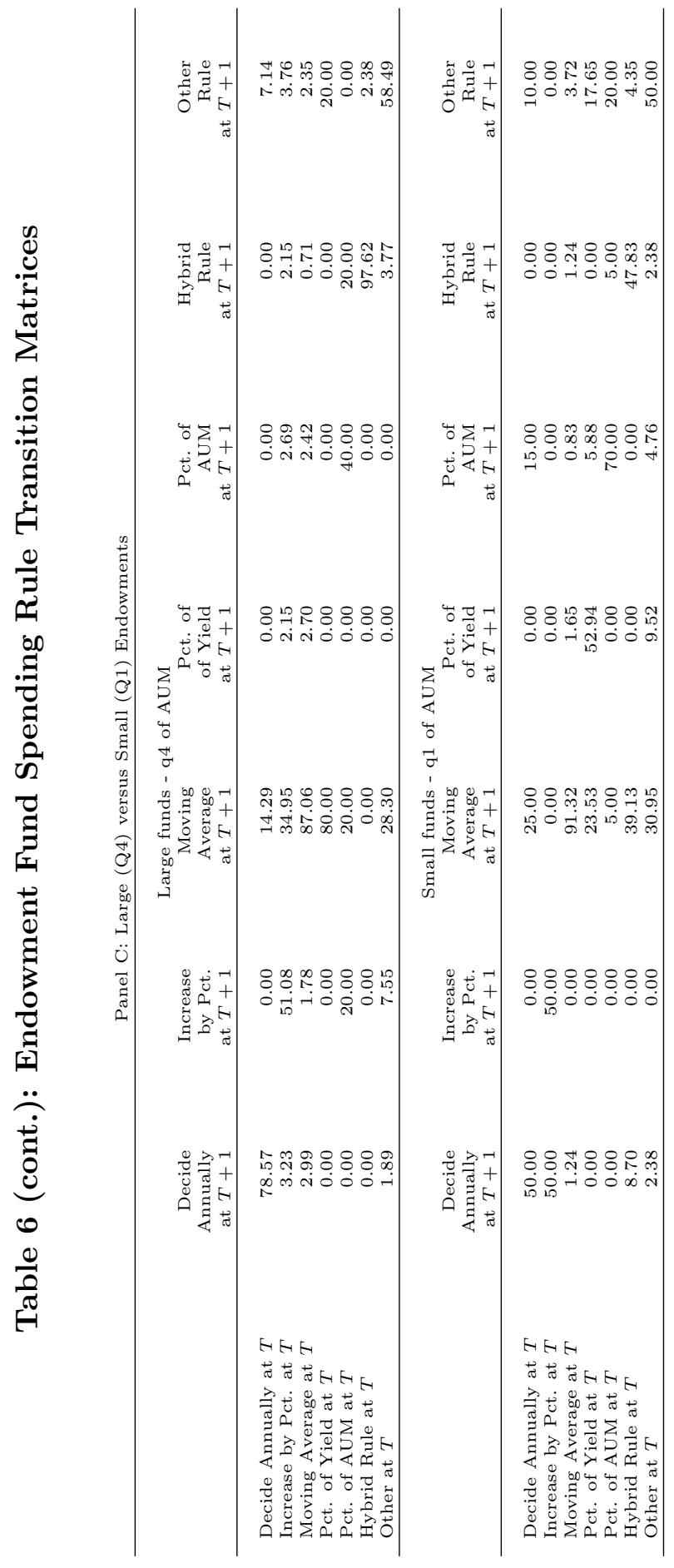




\section{Table 7: The Determinants of Spending Rule Changes}

This table reports regression results examining the determinants of endowment spending rule changes over the period July 1 , 2002 to June 30, 2011. The primary dependent variable $(P O L C H G)$ is an indicator variable assuming a value of 1 if an endowment changed its spending rule in Year $\mathrm{T}+1,0$ otherwise. The base set of potential explanatory factors (observable at Year $\mathrm{T}$ ) includes portfolio net-of-fee return $(R E T)$, actual percentage payout ( $P A Y O U T)$, logarithm of fund size ( $L O G A U M)$, percentage of portfolio invested in alternative assets $(A L T I N V)$, external contributions to the endowment (DONATE), and risk level of the policy-level investment portfolio (VOL). Three different forms of the probit regression in (2) are specified: (i) panel data with Year fixed effects, (ii) panel data with Year and Fund fixed effects, and (iii) Fama-MacBeth. Panel A lists findings for the full sample using all rule changes. Panel B modifies the spending rule change definition to focus on just those changes that also resulted in a higher subsequent payout. Panel $\mathrm{C}$ reports results for the endowment sample quartiles with the highest $(\mathrm{C} 1)$ and lowest $(\mathrm{C} 2)$ average payout-as-percentage-of budget $(P C T B D G T)$ statistics. Panel D reports results for endowment sub-samples that either did not (D1) or did (D2) use special payout appropriation measures. t-statistics are listed parenthetically next to the respective coefficient estimates.

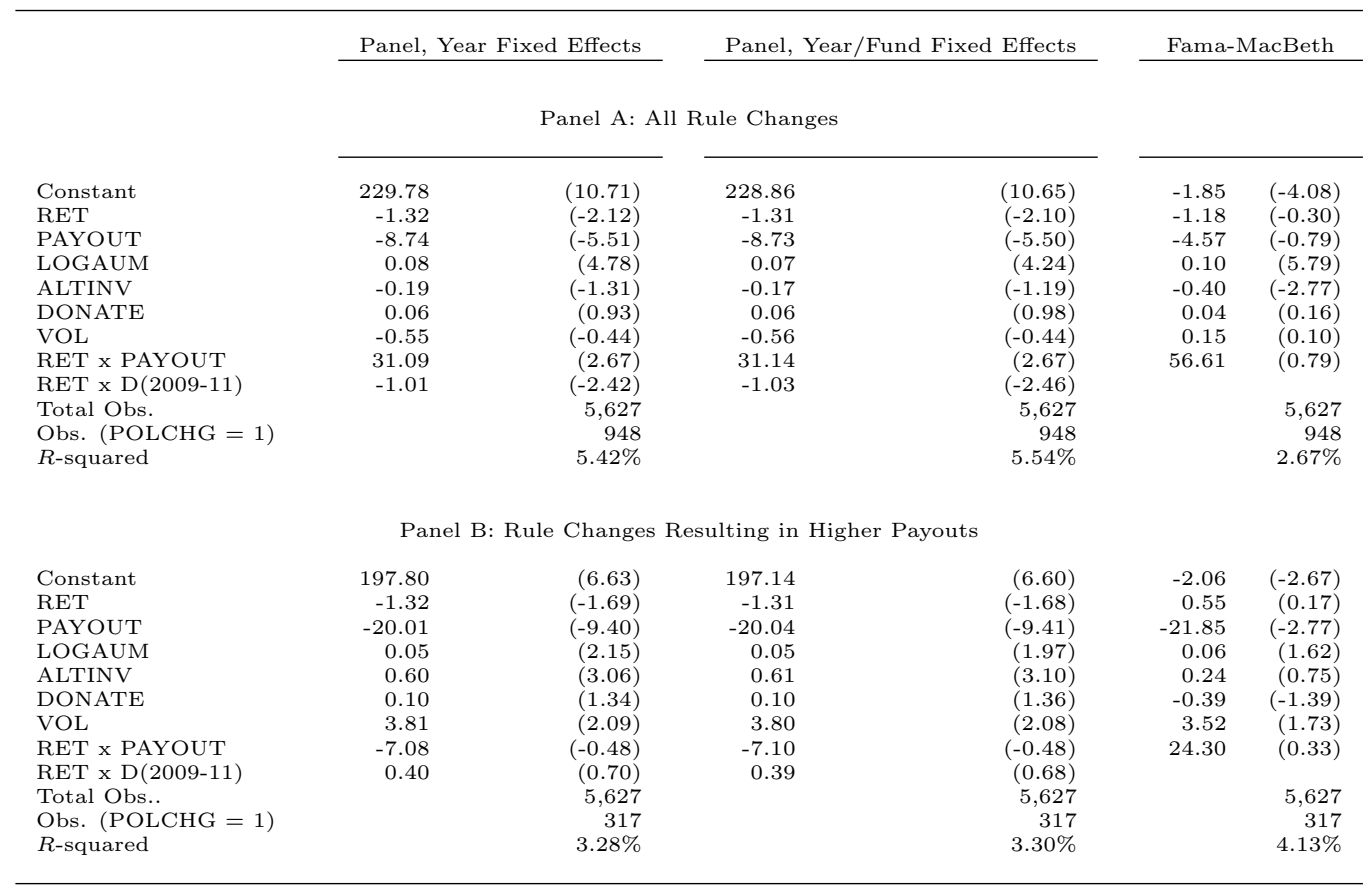

Continued on the next page ... 
Table 7 (cont.): The Determinants of Spending Rule Changes

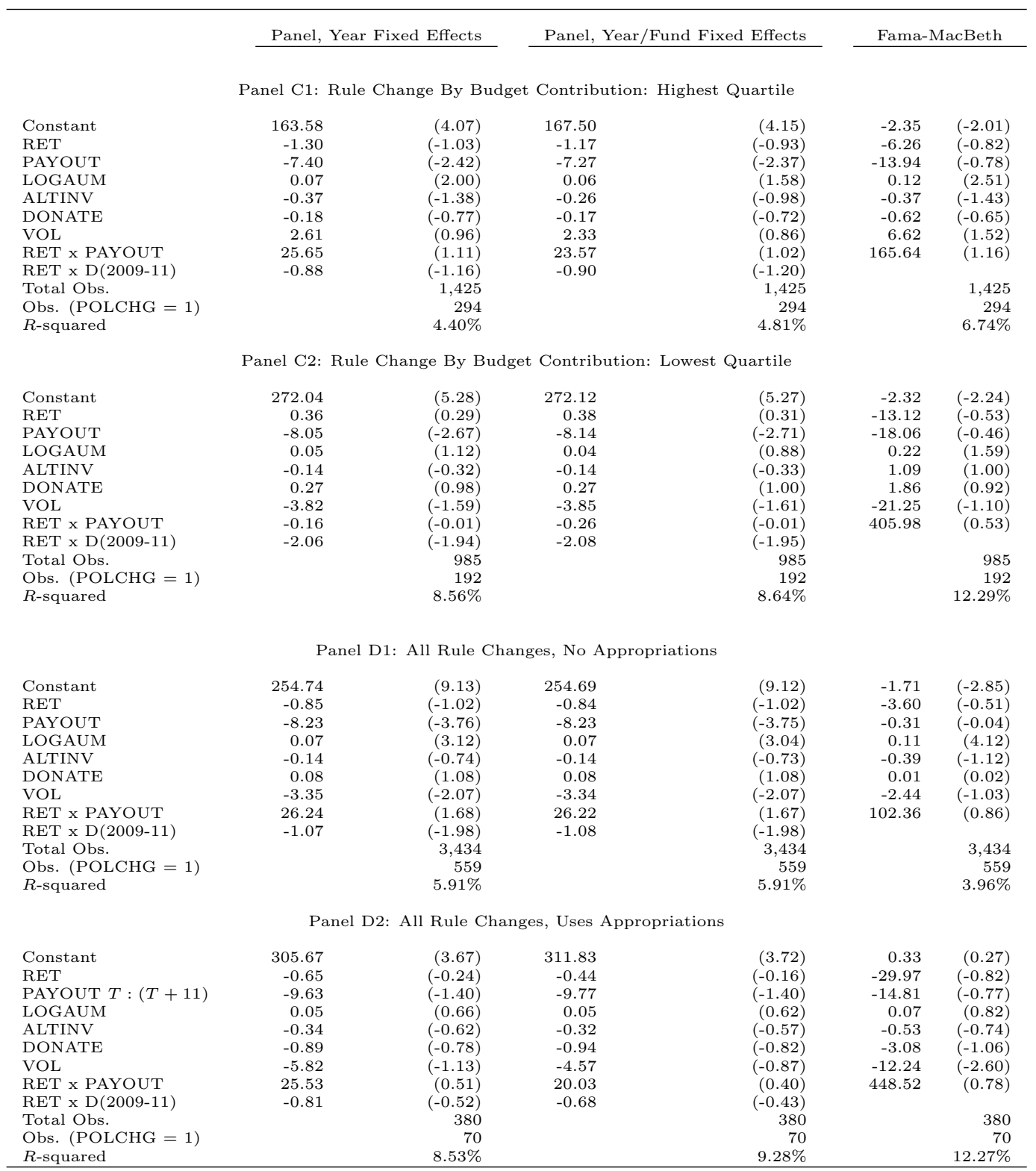




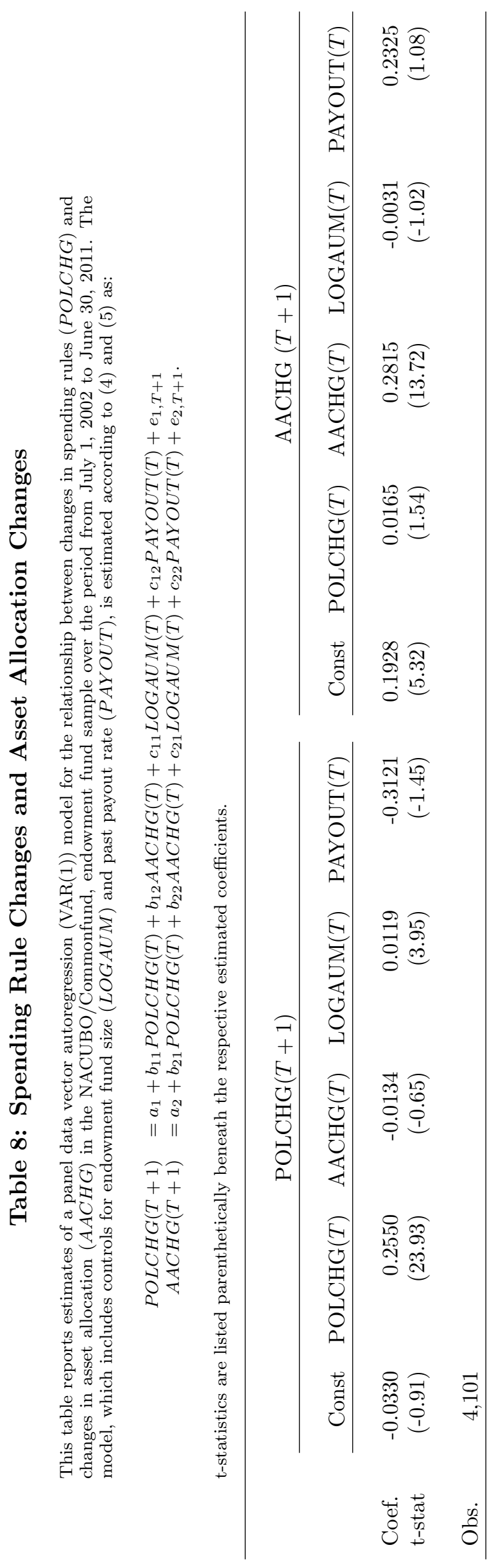


Table 9: Spending Rule Changes and Investment Performance

The table reports investment performance statistics for two non-overlapping sub-samples of the NACUBO/Commonfund endowment sample over the period from July 1, 2002 to June 30, 2011, according to whether an institution either (i) did not change its spending rules (No Change), or (ii) did change its spending rules at least one time (Change). The display shows for each division of the sample average annual returns to the policy benchmark portfolio $\left(R^{B}\right)$ and the benchmark-adjusted performance measure $(A L P H A$, as calculated by the formula in (6). Differences in these return measures for the No Change and Change subgroups are listed, along with the associated t-statistics. Separate sets of statistics are reported for equal-weighted (EW) and value-weighted (VW) portfolios of the respective endowment sub-samples.

\begin{tabular}{lrrrrrr}
\hline & \multicolumn{2}{c}{ EW } & & \multicolumn{2}{c}{ VW } \\
\cline { 2 - 3 } \cline { 5 - 6 } \cline { 5 - 6 } \cline { 5 - 6 } No change & ALPHA & $R^{B}$ & & ALPHA & $R^{B}$ \\
\cline { 2 - 3 } t-stat & $0.90 \%$ & $7.48 \%$ & & $1.35 \%$ & $8.21 \%$ \\
Change & $0.94 \%$ & $7.60 \%$ & & $1.22 \%$ & $8.60 \%$ \\
t-stat & $(0.73)$ & - & & $(0.81)$ & - \\
& & & & & \\
Diff & $-0.04 \%$ & $-0.12 \%$ & & $0.14 \%$ & $-0.39 \%$ \\
t-stat & $(-0.32)$ & $(-1.67)$ & & $(0.27)$ & $(-1.67)$ \\
\hline
\end{tabular}



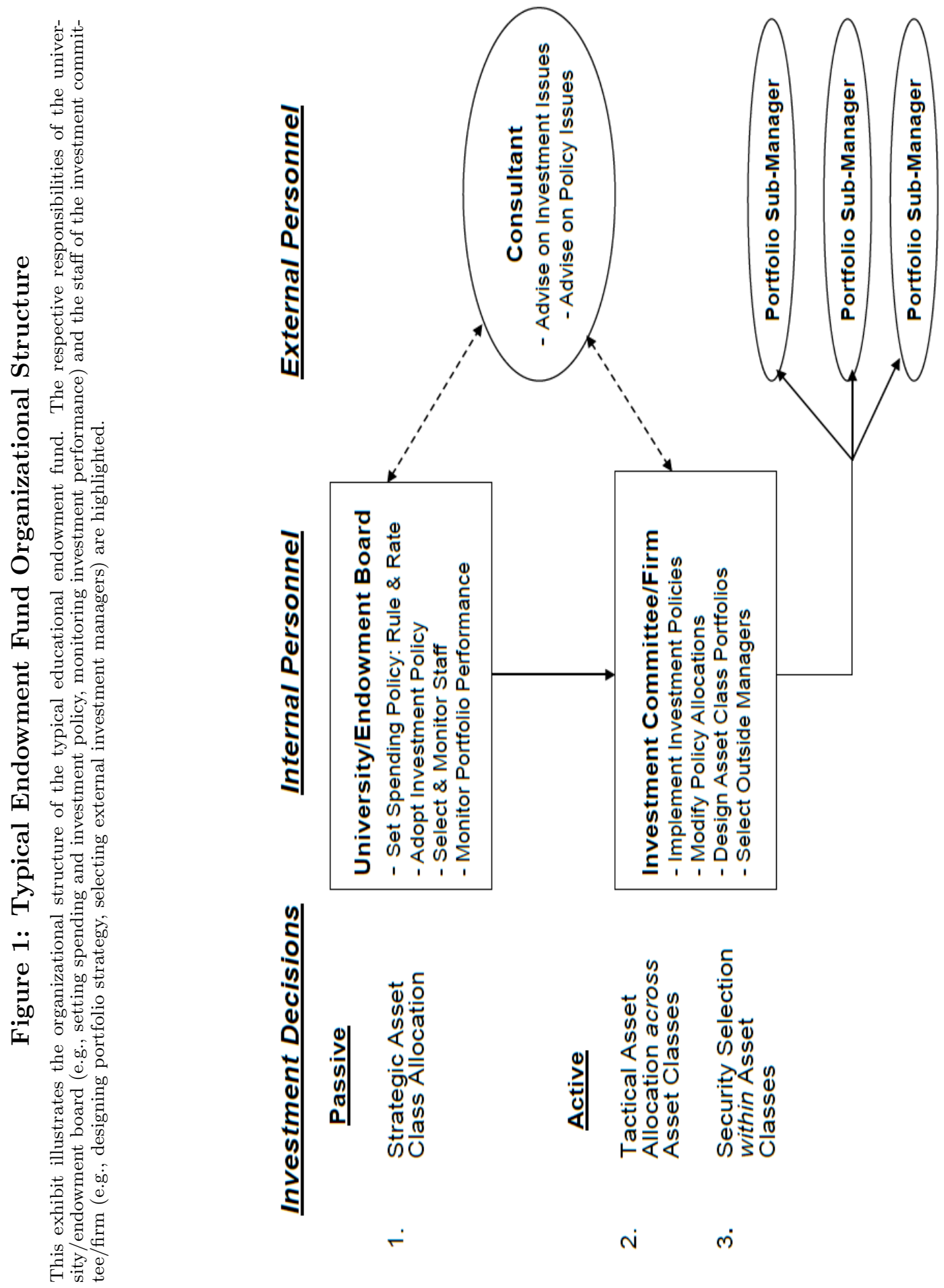

ปิ
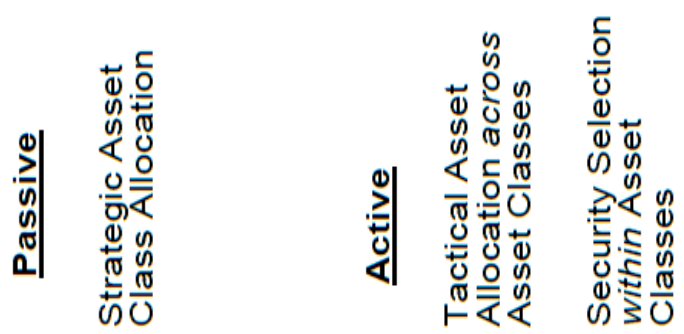
Figure 2: Comparative Asset Allocation Patterns Over Time and Endowment Fund Size

This figure illustrates how mean asset class allocation percentages for the endowment fund sample have changed over time and for portfolios of different size. The ten asset classes reported in the NACUBO/Commonfund surveys are aggregated into the following four categories: Public Equity (U.S. and Non-U.S.), Fixed Income, Alternatives (Hedge Funds, Venture Capital, Private Equity, Real Estate, and Natural Resources), and Cash and Other Assets. Panel A lists asset allocation statistics for funds in different AUM quartiles (largest (Q4) to smallest (Q1)) for two different years (1989 vs. 2011). Panel B lists asset allocation statistics across time $(1989,2003$, and 2011) for two different fund size quartiles (Q4 vs. Q1).

Panel A: Comparison Across AUM Quartiles for Two Years (1989 vs. 2011)

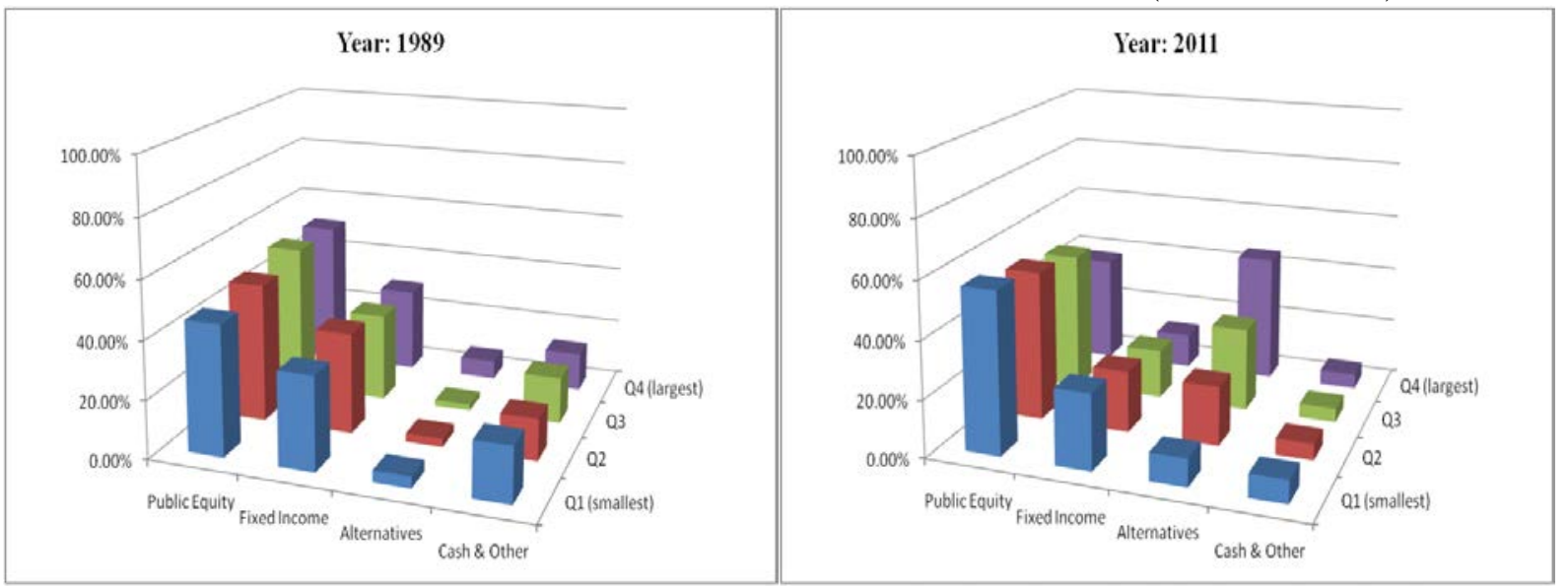

Panel B: Comparison Across Time for Two AUM Quartiles (Q4 (Largest) vs. Q1 (Smallest))

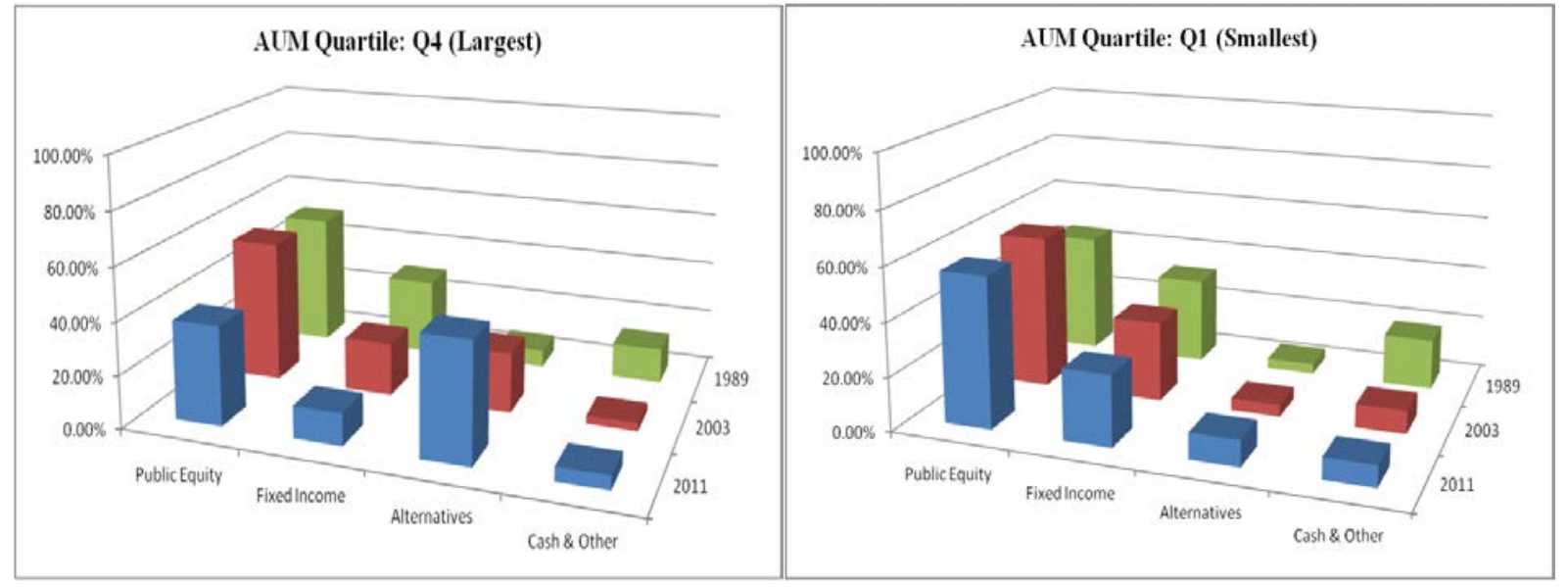


Figure 3: Comparative Spending Rule Patterns Over Time and Endowment Fund Size

This figure illustrates how spending rule adoption frequencies for the endowment fund sample have changed over time and for portfolios of different size. Using the seven categories defined in the Appendix, Panel A lists spending rule frequencies for funds in different AUM quartiles (largest (Q4) to smallest (Q1)) for two different years (2003 vs. 2011). Panel B lists spending rule frequencies across time $(2003,2007$, and 2011) for two different fund size quartiles (Q4 vs. Q1).

Panel A: Comparison Across AUM Quartiles for Two Years (2003 vs. 2011)

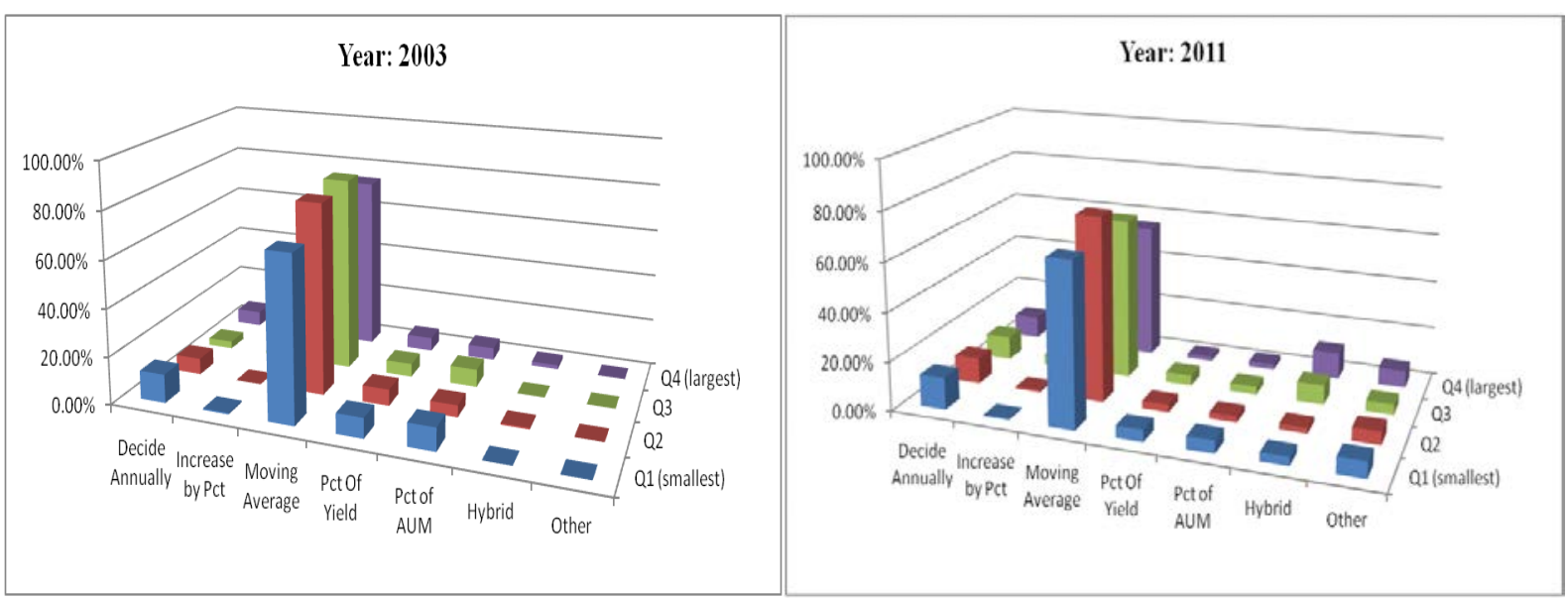

Panel B: Comparison Across Time for Two AUM Quartiles (Q4 (Largest) vs. Q1 (Smallest))

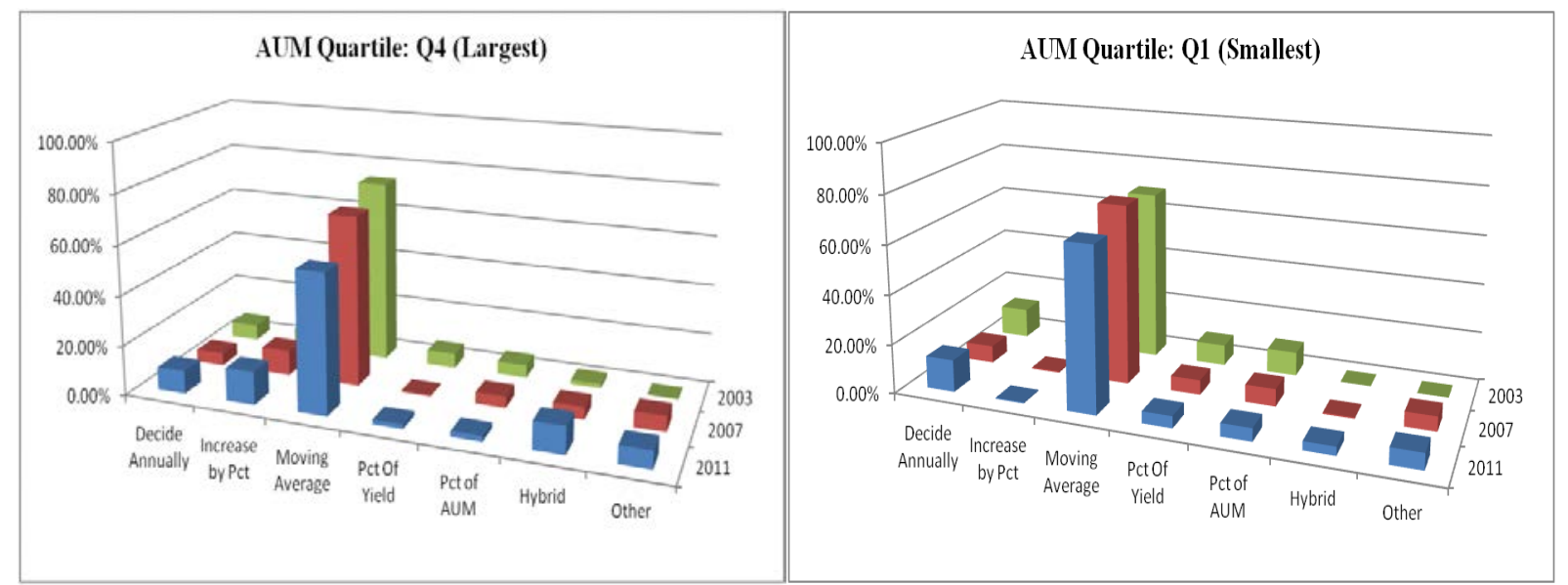




\section{Figure 4: Frequency of Spending Rule Changes}

This figure shows the frequency of spending rule changes for the endowments in the NACUBO/Commonfund sample over the period June 30, 2002 to July 1, 2011. For each endowment that reports sufficient spending policy data for at least two consecutive annual surveys, we calculate the number of times the endowment changes the spending rules it adopted for each fiscal year from 2003 and 2010. The figure depicts the histogram of the number of rule changes.

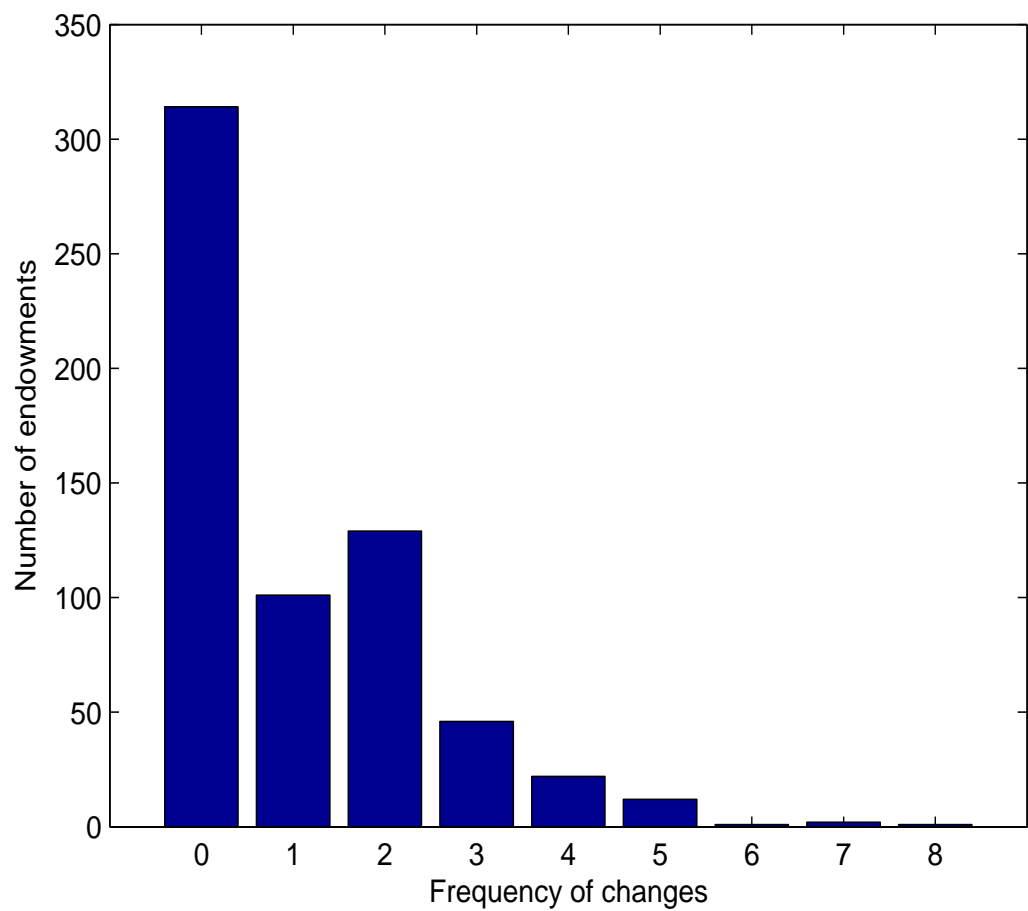

